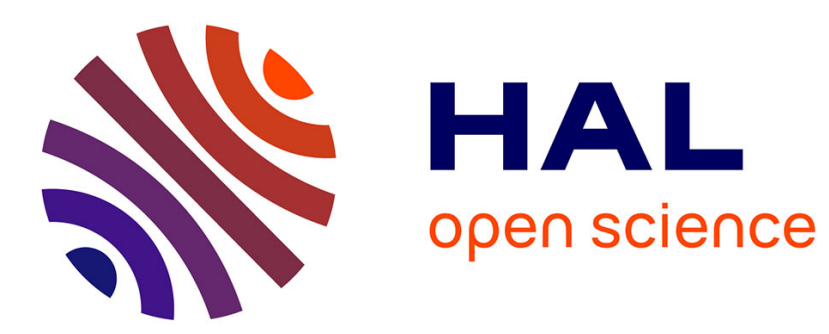

\title{
Exact stationary response of multi-dimensional nonlinear Hamiltonian dynamical systems under parametric and stochastic excitations
}

Christian Soize

\section{- To cite this version:}

Christian Soize. Exact stationary response of multi-dimensional nonlinear Hamiltonian dynamical systems under parametric and stochastic excitations. Journal of Sound and Vibration, 1991, 149 (11), pp.1-24. 10.1016/0022-460X(91)90908-3 . hal-00770314

\section{HAL Id: hal-00770314 https://hal.science/hal-00770314}

Submitted on 3 Apr 2013

HAL is a multi-disciplinary open access archive for the deposit and dissemination of scientific research documents, whether they are published or not. The documents may come from teaching and research institutions in France or abroad, or from public or private research centers.
L'archive ouverte pluridisciplinaire HAL, est destinée au dépôt et à la diffusion de documents scientifiques de niveau recherche, publiés ou non, émanant des établissements d'enseignement et de recherche français ou étrangers, des laboratoires publics ou privés. 


\title{
Exact Stationary-Response of Multi-Dimensional Nonlinear Hamiltonian Dynamical Systems Under Parametric and External Stochastic Excitations
}

\author{
C. Soize \\ Office National d'Etudes et de Recherches Aérospatiales \\ 29, Avenue de la Division Leclerc \\ 92330 Chatillon sous Bagneux, France
}

\section{Introduction}

For many years, numerous publications have been written on the Fokker-Planck (FKP) equation method for studying the stochastic response of nonlinear dynamical systems under random excitations (parametric and inhomogeneous terms). The first step is to obtain the FKP equation. For most problems, this step is not immediate and a stochastic modelling has to be performed. The second step is to solve the FKP equation which is a parabolic partial differential equation with initial and boundary conditions. Generally, the exact solution cannot be explicitly obtained, except for very special first or second order nonlinear systems. For instance, one can refer to the the recent publication [1] written in the context of the theoretical physics.

For the nonlinear dynamical systems (second order systems), the difficulties increase because the diffusion operator is not a positive-definite. The exact solution can be obtain only for the steady-state FKP equation related to the existence of an asymptotic stationary solution (a.s.s.). For the mechanical applications, theorically this stool allows to study the response of nonlinear oscillators to stochastic excitations in the diffusive Markov process context $[2,3,4,5,6]$.

(i) -The one dimensional nonlinear oscillator under an external stationary gaussian random excitation has been studied extensively in the last two decades.

- If the external excitation is a white noise, the exact steady-state probability density function (p.d.f.) is known in a sufficiently general case for the a.s.s. $[7,8]$. 
- If the external excitation is not a white noise, but a colored process, which is a physically realizable stationary gaussian process, a Markov realization can be performed to obtain the FKP equation $[4,6]$. Unfortunately, no exact solution exists in this situation and an approximate method must be used to solve the FKP equation. For this reason, the stochastic averaging method has been developped [9,10,11,12,13,14,15,16].

- In the case where there are simultaneously a parametric and an external stationary gaussian white noise excitation,exact solutions for the a.s.s. are pratically non existent in the litterature. Recently, in ref [18], the authors gave two examples for which an exact steadystate p.d.f. is obtained from the steady-state FKP equation, in using the principle of detailed balance.

(ii) - For multi-dimensional nonlinear oscillator under external stationary gaussian white noise excitations, the situation is different and very little is known. The exact steady-state p.d.f., related to the existence of an a.s.s., has been obtained for some specific multidimensional nonlinear oscillators $[1,2,17,19,20]$. When a parametric gaussian white noise excitation is present in addition to the external noise, only one simple example of exact steady state p.d.f. is given in [18].

In the general case, no exact solution can be obtained and numerical methods must be used. Unfortunately, the numerical methods for solving the F.K.P. equation in higher dimension are very difficult to perform [17]. This is the reason why the F.K.P. method is not used in this situation and approximate methods have been developped such as : thestochastic linearization method $[3,4,21,22,23,24]$, and the most general approximate method, the direct numerical simulation method $[25,26,27,28]$.

(iii) - The purpose of the present paper is to study the exact steady-state p.d.f. of the a.s.s. of a large class of multi-dimensional nonlinear Hamiltonian dissipative dynamical systems under parametric and external random excitations, using the F.K.P. equation method. The dynamic system of concern may be linear or nonlinear ad has an arbitrary finite number of degrees of freedom. The conservative part is a general Hamiltonian formulation for time invariant nonlinear dynamical systems. The non conservative part has three terms : a linear or a nonlinear damping term, an external random excitation which appears as the inhomogeneous term, and a general random parametric excitation term which appears in the coefficients of the unknowns. The parametric and external random excitations are second order centered stationary gaussian wide-band stochastic processes. The band-width is sufficiently high to reasonably allow be used of a white noise model. Therefore, the 
modelling stochastic differential equation (SDE) is obtained in the Stratonovich's sense [29] when the band-width of the excitation noises tends towards infinity.

In transforming, classically $[29,30,6]$ the Stratonovich SDE into an Itô stochastic differential equation (ISDE), one can use the basic tools for the treatment of diffusive Markov processes $[4,6,30,31,32,33,34,35]$. Thus, the existence and uniqueness of a regular solution of the ISDE with random initial condition can be studied. This point is very important because the random parametric excitation causes some time variations of the dynamic characteristics of the system. Therefore the stability of the system can be affected and must be studied. On the other hand, after the existence of this unique regular solution has been proved, it is necessary to study the existence of an asymptotic stationary solution (a.s.s.). This point is difficult enough the prove in the general case from a mathematical point of view. Only then, the steady-state p.d.f. can be viewed as the solution of the steady F.K.P. equation. For the multi-dimentional Hamiltonian nonlinear dynamical systems studied in this article, we shall build the exact steady-state p.d.f. . When random parametric excitations vanish, the corresponding class of nonlinear dynamical systems contains the results from ref $[8,20]$. When random parametric excitations exist, the corresponding class contains the result from ref [18] concerning the multi-dimensional example.

Before presenting several examples at the end of section 2, we shall study the integrability of the steady-state p.d.f. because, for the multi-dimentional case, the result is not selfevident.

In a second part of this article (section 3), we shall give some complements for the particular case where the Hamiltonian function has a radial form. In this case, one can explicitly calculate the Fourier transform of the p.d.f. (characteristic function) and the covariance operator. 


\section{Exact steady-state p.d.f. for a class of nonlinear Hamiltonian dissipative dynamical systems under parametric and external physical gaussian wide-band noise excitations}

\subsection{Notations}

Let $\mathrm{x}=\left(\mathrm{x}_{1}, \cdots, \mathrm{x}_{\mathrm{m}}\right)$ be a $\mathbb{R}^{\mathrm{m}}$ vector. We identify the $\mathrm{x}$ vector with the $(\mathrm{m} \times 1)$ column matrix of its $x_{j}$ components. The Euclidian space $\mathbb{R}^{\mathrm{m}}$ is equipped with the usual inner product $\langle\mathrm{x}, \mathrm{y}\rangle=\sum_{\mathrm{j}=1}^{\mathrm{m}} \mathrm{x}_{\mathrm{j}} \mathrm{y}_{\mathrm{j}}, \mathrm{x}$ and $\mathrm{y}$ in $\mathbb{R}^{\mathrm{m}}$, and the associated norm $\|\mathrm{x}\|=\langle\mathrm{x}, \mathrm{x}\rangle^{1 / 2}$. We denote (1) - by Mat (n,m) the set of all the ( $\times$ m) real matrices ; (2) - by $[\mathrm{a}]^{\mathrm{T}} \in \operatorname{Mat}(\mathrm{m}, \mathrm{n})$ the transpose of $[\mathrm{a}] \in \operatorname{Mat}(\mathrm{n}, \mathrm{m}) ;(3)-$ by $\|I \mathrm{a}\| \mathrm{I}=\left(\sum_{\mathrm{j}=1}^{\mathrm{n}} \sum_{\mathrm{k}=1}^{\mathrm{m}}[\mathrm{a}]_{\mathrm{jk}}^{2}\right)^{1 / 2}$.

Let $\mathrm{x}, \mathrm{y} \rightarrow \mathrm{h}(\mathrm{x}, \mathrm{y})$ be a real function defined on $\mathbb{R}^{\mathrm{m}} \times \mathbb{R}^{\mathrm{m}}$. For $\mathrm{z} \in\{\mathrm{x}, \mathrm{y}\}$ we shall denote by $\partial_{\mathrm{z}} \mathrm{h}$ and $\partial_{\mathrm{Z}}^{2} \mathrm{~h}$ respectively the $\mathbb{R}^{\mathrm{m}}$ - vector and the $(\mathrm{n} \times \mathrm{m})$ real matrix such that :

$$
\left(\partial_{\mathrm{z}} \mathrm{h}\right)_{\mathrm{j}}=\frac{\partial \mathrm{h}}{\partial \mathrm{z}_{\mathrm{j}}} \quad ; \quad\left[\partial_{\mathrm{z}}^{2} \mathrm{~h}\right]_{\mathrm{jk}}=\frac{\partial^{2} \mathrm{~h}}{\partial \mathrm{z}_{\mathrm{j}} \partial \mathrm{z}_{\mathrm{k}}}
$$

A $\mathrm{C}^{\mathrm{P}}$-function defined on $\mathbb{R}^{\mathrm{m}}$ with values in $\mathbb{R}^{\mathrm{n}}$ is a function which is $\mathrm{p}$-times continuously differentiable on $\mathbb{R}^{\mathrm{m}}$

\subsection{Canonical equations with physical gaussian wide-band noises}

We consider a nonlinear dynamical system of dimension $\mathrm{m} \geq 1$, described in the canonical form.

Let $Q(t)=\left(Q_{1}(t), \cdots, Q_{m}(t)\right)$ be generalized coordinates and $\dot{Q}(t)=\frac{d Q(t)}{d t}$ the generalized velocity. We denote by $P(t)=\left(P_{1}(t), \cdots, P_{m}(t)\right)$ the generalized momentum canonically conjugated from $Q(t)$. Let $p=\left(p_{1}, \cdots, p_{m}\right)$ and $q=\left(q_{1}, \cdots, q_{m}\right)$ be the variables associated with the $\mathrm{P}(\mathrm{t})$ and $\mathrm{Q}(\mathrm{t})$ stochastic processes. We consider the following nonlinear stochastic differential equation on $\mathbb{R}^{\mathrm{m}} \times \mathbb{R}^{\mathrm{m}}$ defined by :

$$
\left.\begin{array}{l}
\dot{Q}=\partial_{\mathrm{p}} \mathrm{H}(\mathrm{Q}, \mathrm{P}) \\
\dot{\mathrm{P}}=-\partial_{\mathrm{q}} \mathrm{H}(\mathrm{Q}, \mathrm{P})+\mathrm{F}\left(\mathrm{Q}, \mathrm{P}, \eta,\left[\xi_{1}\right], \cdots,\left[\xi_{\mathrm{J}}\right]\right)
\end{array}\right\}
$$


for $\mathrm{t}>0$, with the random initial condition :

$$
\mathrm{Q}(0)=\mathrm{Q}_{0} \quad, \quad \mathrm{P}(0)=\mathrm{P}_{0} \quad \text { a.s. }
$$

where :

(i) - The Hamiltonian function of the corresponding associated conservative system

(i.e. $\mathrm{F} \equiv 0$ ) is denoted by $\mathrm{H}$. We shall assume that :

$(\mathrm{i}-1): \mathrm{q}, \mathrm{p} \rightarrow \mathrm{H}(\mathrm{q}, \mathrm{p})$ is a twice continuously differentiable function defined on $\mathbb{R}^{\mathrm{m}} \times \mathbb{R}^{\mathbf{m}}$ with values in $\mathbb{R}^{+}=[0,+\infty[$, independent of time $t$;

(i-2) : for all $\mathrm{p}$ and $\mathrm{q}$ in $\mathbb{R}^{\mathrm{m}}$, the $(\mathrm{m} \times \mathrm{m})$ real symmetrical matrix $\left[\partial_{\mathrm{p}}^{2} \mathrm{H}\right]$ is a positivedefinite ;

(i-3) : the mapping $p, q \rightarrow\left[\partial_{\mathrm{p}}^{2} \mathrm{H}\right]$ is bounded on $\mathbb{R}^{\mathrm{m}} \times \mathbb{R}^{\mathrm{m}}$.

(i-4) : function $\mathrm{H}$ is such that :

$$
\operatorname{Inf}_{\|q\|^{2}+\|p\|^{2}>R^{2}} H(q, p) \rightarrow+\infty \text { if } R \rightarrow+\infty
$$

Note that assumptions (i-2) and (i-3) yield the following inequalities for all $\mathrm{p}$ and $\mathrm{q}$ in $\mathbb{R}^{\mathrm{m}}$ :

$$
0<\left\langle\left[\partial_{\mathrm{p}}^{2} \mathrm{H}\right] \mathrm{z}, \mathrm{z}\right\rangle \leq \mathrm{C}_{\mathrm{T}}\|\mathrm{z}\|^{2} \quad, \forall \mathrm{z} \in \mathbb{R}^{\mathrm{m}} \quad,\|\mathrm{z}\|>0
$$

where $\mathrm{C}_{\mathrm{T}}$ is a positive real constant which does not depend on $\mathrm{p}$ and $\mathrm{q}$.

(ii) - The non conservative force $\mathrm{F}=\left(\mathrm{F}_{1}, \cdots, \mathrm{F}_{\mathrm{m}}\right)$ is expressed in terms of the canonical variables and is written as :

$F\left(Q, P, \eta,\left[\xi_{1}\right], \cdots,\left[\xi_{J}\right]\right)=-f(H)[G] \dot{Q}+g(H)[S] \eta(t)-\varepsilon_{m} \sum_{j=1}^{J}[S]\left[\xi_{j}(t)\right] \mathbb{U}^{(j)}(Q, \dot{Q})$

with $\dot{Q}=\partial_{\mathrm{p}} \mathrm{H}$ ( first equation (1) ), and where the three terms of the right hand side of equation (5) are respectively : a nonlinear damping term, an external excitation term with a possible parametric effect, and a general parametric excitation term. We have used in the définition of $\mathrm{F}$ the following assumptions and notations :

(ii-1) : The $(\mathrm{m} \times \mathrm{m})$ real matrices $[\mathrm{S}]$ and $[\mathrm{G}]$ are constant and $[\mathrm{S}]$ is such that $[\mathrm{G}]=[\mathrm{S}][\mathrm{S}]^{\mathrm{T}}$ is a positive-definite matrix;

(ii-2) : Functions $f$ and $g$ are continuous on $\mathbb{R}^{+}$, with values in $\left.\mathbb{R}^{+*}=\right] 0,+\infty[$ and $g$ is continuously differentiable;

(ii-3) : $\mathrm{J}$ is a positive integer, $\varepsilon_{\mathrm{m}}$ is a real constant. When $\varepsilon_{\mathrm{m}}=0$, the general parametric excitation vanishes. For $\mathrm{j} \in\{1, \cdots, \mathrm{J}\}, \mathrm{q}, \mathrm{p} \rightarrow \mathrm{U}^{(\mathrm{j})}(\mathrm{q}, \mathrm{p})=\mathbb{U}^{(\mathrm{j})}\left(\mathrm{q}, \partial_{\mathrm{p}} \mathrm{H}\right)$ are given 
continuous functions defined on $\mathbb{R}^{\mathrm{m}} \times \mathbb{R}^{\mathrm{m}}$ with values in $\mathbb{R}^{\mathrm{m}}$. For all $\mathrm{q}$ in $\mathbb{R}^{\mathrm{m}}$, functions $p \rightarrow U^{(j)}(q, p)$ are continuously differentiable. The functions $U^{(1)}, \ldots, U^{(J)}$ are such that :

$$
\sum_{j=1}^{J}\left\|U^{(j)}(q, p)\right\|^{2}=2 \gamma(H)
$$

where $r \rightarrow \gamma(r)$ is a $C^{1}$-function on $\mathbb{R}^{+}$with values in $\mathbb{R}^{+}$. (ii-4) : The $\mathbb{R}^{m}$-valued stochastic process $\eta(t)=\left(\eta_{1}(t), \cdots, \eta_{m}(t)\right)$ and the Mat $(m, m)$ valued stochastic processes $\left[\xi_{1}(t)\right], \cdots,\left[\xi_{J}(t)\right]$ are given second order centered, stationary gaussian wide-band physical noises.

Let be $\Re=\mathrm{m}+\mathrm{J} \mathrm{m}^{2}$. We assume that : (1) the $\Re$ real-valued processes $\left(\eta_{\mathrm{i}},\left[\xi_{\mathrm{j}}\right]_{\mathrm{lk}} ; \mathrm{i}, 1, \mathrm{k} \in\{1, \cdots, \mathrm{m}\}, \mathrm{j} \in\{1, \cdots, \mathrm{J}\}\right)$ are independent stochastic processes ; (2) processes $\eta_{i},\left[\xi_{j}\right]_{l k}$ tend towards the real-valued normalized gaussian white noises denoted respectively by $\dot{W}_{\mathrm{i}}^{0}$ and $\dot{W}_{\mathrm{k}}^{\mathrm{j} 1}$, when the band-width tends towards infinity. We let $\dot{W}^{0}=\left(\dot{W}_{1}^{0}, \cdots, \dot{W}_{m}^{0}\right)$ and $\dot{W}^{j 1}=\left(\dot{W}_{1}^{j 1}, \cdots, \dot{W}_{m}^{j 1}\right)$. We introduce the $\mathbb{R}^{\Re}$-valued normalized gaussian white noise $\mathbf{W}$ such that :

$$
[\dot{\mathrm{W}}]^{\mathrm{T}}=\left(\left[\dot{\mathrm{W}}^{0}\right]^{\mathrm{T}} ;\left[\dot{\mathrm{W}}^{11}\right]^{\mathrm{T}}, \cdots,\left[\dot{\mathrm{W}}^{1 \mathrm{~m}}\right]^{\mathrm{T}} ; \cdots ;\left[\dot{\mathrm{W}}^{\mathrm{J} 1}\right]^{\mathrm{T}}, \cdots,\left[\dot{\mathrm{W}}^{\mathrm{Jm}}\right]^{\mathrm{T}}\right)
$$

Let $W(t)=\left(W_{1}(t), \cdots, W_{\eta}(t)\right)$ the $\mathbb{R}^{\Re}$-valued normalized Wiener process on $\mathbb{R}^{+}$. Its Mat $(\boldsymbol{\eta}, \mathfrak{\eta})$ - valued covariance function is $\left[\mathrm{CW}_{\mathrm{W}}\left(\mathrm{t}, \mathrm{t}^{\prime}\right)\right]=\min \left(\mathrm{t}, \mathrm{t}^{\prime}\right)[\mathrm{I}]$, where $[\mathrm{I}]$ denotes the $(\Re \times \Re)$ unit matrix. We know that the process $\dot{W}$, defined by (7), must be viewed in the sense of the theory generalized stochastic processes [6] as the derivative of $W$ with respect to $t$.

(iii) The initial condition $\left(\mathrm{Q}_{0}, \mathrm{P}_{0}\right)$ is a given $\mathbb{R}^{\mathrm{m}} \times \mathbb{R}^{\mathrm{m}}$-valued second order random variable which is independent from $\{W(t), t \geq 0\}$.

\subsection{Stochastic modelling of the canonical equations}

By assumptions, the stationary wide-band stochastic processes $\eta$ and $\left[\xi_{j}\right]$ have sufficiently high band-width for a white noise model to be used. In these conditions, we know [29] that the stochastic problem (1)-(2)-(5) is equivalent to the following Stratonovitch stochastic differential equation on $\mathbb{R}^{\mathrm{m}} \times \mathbb{R}^{\mathrm{m}}$ when the band-width of the excitation stochastic processes tends towards infinity :

$$
d\left(\begin{array}{l}
Q(t) \\
P(t)
\end{array}\right)=\hat{b}(Q(t), P(t)) d t+[\hat{a}(Q(t), P(t))] \circ d W(t)
$$


where the symbol $\circ \mathrm{dW}(\mathrm{t})$ means that the stochastic differential calculus must be read in the Stratonovitch's sense $[29,30]$. The vector $\widehat{b}(q, p) \in \mathbb{R}^{m} \times \mathbb{R}^{m}$ is such that :

$$
\hat{b}(q, p)=\left(\begin{array}{c}
\partial_{p} H \\
-\partial_{q} H-f(H)[G] \partial_{p} H
\end{array}\right)
$$

The matrix $[\hat{a}(q, p)] \in \operatorname{Mat}(2 \mathrm{~m}, \mathfrak{\eta})$ is given by :

$$
[\hat{a}(\mathrm{q}, \mathrm{p})]=\left[\begin{array}{c}
\mathrm{O} \\
\mathrm{a}(\mathrm{q}, \mathrm{p}))
\end{array}\right]
$$

where $[0]$ denotes the $(\mathrm{m} \times \Re)$ null matrix and $[\mathrm{a}(\mathrm{q}, \mathrm{p})]$ is the $(\mathrm{m} \times \Re)$ real matrix:

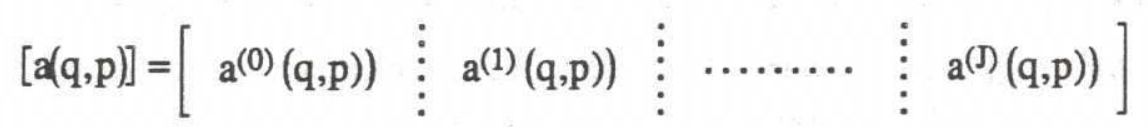

with $\left.\mathrm{a}^{(0)}(\mathrm{q}, \mathrm{p})\right) \in \operatorname{Mat}(\mathrm{m}, \mathrm{m})$ and $\left.\mathrm{a}^{(\mathrm{j})}(\mathrm{q}, \mathrm{p})\right) \in \operatorname{Mat}\left(\mathrm{m}, \mathrm{m}^{2}\right)$ the matrices defined by :

$$
\left.\mathrm{a}^{(0)}(\mathrm{q}, \mathrm{p})\right)=\mathrm{g}(\mathrm{H})[\mathrm{S}]
$$

and for $\mathrm{j} \in\{1, \cdots, \mathrm{J}\}$ :

$$
\left[\mathrm{a}^{(\mathrm{j})}(\mathrm{q}, \mathrm{p})\right]=-\varepsilon_{\mathrm{m}}\left[\begin{array}{ccc}
{[\mathrm{S}]_{11} \mathrm{U}^{(\mathrm{j})}(\mathrm{q}, \mathrm{p})^{\mathrm{T}}} & \cdots \cdots \cdots \cdots \cdots & {[\mathrm{S}]_{1 \mathrm{~m}} \mathrm{U}^{(\mathrm{j})}(\mathrm{q}, \mathrm{p})^{\mathrm{T}}} \\
\vdots & \vdots & \vdots \\
\vdots \mathrm{S}]_{\mathrm{m} 1} \mathrm{U}^{(\mathrm{j})}(\mathrm{q}, \mathrm{p})^{\mathrm{T}} & \cdots \cdots \cdots \cdots & \vdots \mathrm{S}]_{\mathrm{mm}} \mathrm{U}^{(\mathrm{j})}(\mathrm{q}, \mathrm{p})^{\mathrm{T}}
\end{array}\right]
$$

The Stratonovich stochastic differential equation (8) can be transformed $[29,30,6]$ into the following Itô stochastic differential equation on $\mathbb{R}^{\mathrm{m}} \times \mathbb{R}^{\mathrm{m}}$ :

$$
d\left(\begin{array}{l}
Q(t) \\
P(t)
\end{array}\right)=b(Q(t), P(t)) d t+[\hat{a}(Q(t), P(t))] d W(t)
$$

where the drift vector $\mathrm{b}(\mathrm{q}, \mathrm{p}) \in \mathbb{R}^{\mathrm{m}} \times \mathbb{R}^{\mathrm{m}}$ is given by

$$
b(q, p)=\left(\begin{array}{c}
b^{(q)}(q, p) \\
b^{(p)}(q, p)
\end{array}\right)=\left(\begin{array}{c}
\partial_{p} H \\
-\partial_{q} H-f(H)[G] \partial_{p} H+b^{c}(q, p)
\end{array}\right)
$$

and where $b^{c}(q, p)=\left(b_{1}^{c}(q, p), \cdots, b_{m}^{c}(q, p)\right)$ is the added $\mathbb{R}^{m}$-valued drift vector which is 
written, for $l \in\{1, \cdots, m\}$, as :

$$
\mathrm{b}_{\mathrm{l}}^{\mathrm{c}}(\mathrm{q}, \mathrm{p})=\frac{1}{2} \sum_{\mathrm{k}=1}^{\mathrm{m}} \sum_{\mathrm{i}=1}^{\Re}[\mathrm{a}(\mathrm{q}, \mathrm{p})]_{\mathrm{ki}} \frac{\partial}{\partial \mathrm{p}_{\mathrm{k}}}[\mathrm{a}(\mathrm{q}, \mathrm{p})]_{\mathrm{li}}
$$

Using (11), we obtain :

$$
\mathrm{b}^{\mathrm{c}}(\mathrm{q}, \mathrm{p})=\frac{1}{2}\left(\mathrm{~g}(\mathrm{H}) \mathrm{g}^{\prime}(\mathrm{H})+\varepsilon_{\mathrm{m}}^{2} \gamma^{\prime}(\mathrm{H})\right)[\mathrm{G}] \partial_{\mathrm{p}} \mathrm{H}
$$

where $g^{\prime}$ and $\gamma^{\prime}$ are respectively the derivatives of $g$ and $\gamma$ with respect to $H$.

The diffusion matrix $[\hat{\sigma}(\mathrm{q}, \mathrm{p})]=[\hat{\mathrm{a}}(\mathrm{q}, \mathrm{p})][\hat{\mathrm{a}}(\mathrm{q}, \mathrm{p})]^{\mathrm{T}} \in \operatorname{Mat}(2 \mathrm{~m}, 2 \mathrm{~m})$ is written as:

$$
[\hat{\sigma}(\mathrm{q}, \mathrm{p})]=\left[\begin{array}{cc}
0 & 0 \\
0 & \sigma(\mathrm{q}, \mathrm{p})
\end{array}\right]
$$

where $\mathrm{O}$ denotes the $(\mathrm{m} \times \mathrm{m})$ null matrix, and where

$$
[\sigma(\mathrm{q}, \mathrm{p})]=[\mathrm{a}(\mathrm{q}, \mathrm{p})][\mathrm{a}(\mathrm{q}, \mathrm{p})]^{\mathrm{T}} \in \operatorname{Mat}(\mathrm{m}, \mathrm{m})
$$

In talking into account the definition (11) of $[\mathrm{a}(\mathrm{q}, \mathrm{p})]$, we see that :

$$
[\sigma(q, p)]=\sum_{j=0}^{J}\left[a^{(j)}(q, p)\right]\left[a^{(j)}(q, p)\right]^{T}
$$

Finally, the explicit calculation of the above axpression yields :

$$
[\sigma(\mathrm{q}, \mathrm{p})]=\left(\mathrm{g}^{2}(\mathrm{H})+2 \varepsilon_{\mathrm{m}}^{2} \gamma(\mathrm{H})\right)[\mathrm{G}]
$$

\subsection{Existence and uniqueness of a regular solution, and FKP equation}

We assume that the Ito stochastic differential equation (12) with the random initial condition (2), has a unique solution $(\mathrm{Q}(\mathrm{t}), \mathrm{P}(\mathrm{t}))$ which (1) is a $\mathbb{R}^{\mathrm{m}} \times \mathbb{R}^{\mathrm{m}}$-valued diffusive Markov process ; (2) is an almost surely (a.s.) continuous stochastic process ; (3)is defined a.s. for $t \geq 0$ (one says that the process does not explode). Let $\tau$ be the transition probability of the process $(\mathrm{Q}(\mathrm{t}), \mathrm{P}(\mathrm{t}))$ which is such that :

$$
\begin{aligned}
B_{q}, B_{p} \rightarrow \mathcal{T}( & \left(q_{0}, p_{0} ; t ; B_{q}, B_{p}\right) \\
& =\operatorname{Proba}\left(Q(t) \in B_{q}, P(t) \in B_{p} \mid Q(0)=q_{0}, P(0)=p_{0}\right), t>0,
\end{aligned}
$$


where $\mathrm{B}_{\mathrm{q}}$ and $\mathrm{B}_{\mathrm{p}}$ are some arbitrary Borel sets of $\mathbb{R}^{\mathrm{m}}$, and $\mathrm{q}_{0}$ and $\mathrm{p}_{0}$ any $\mathbb{R}^{\mathrm{m}}$-vectors. In addition, we assume that the probability distribution of the initial r.v $\left(\mathrm{Q}_{0}, \mathrm{P}_{0}\right)$ has a density $P_{Q_{0}, P_{0}}(q, p)$ with respect to dq dp.

Hence for every $t \geq 0$, the probability distribution of the random variable $(Q(t), P(t))$ has a density $\rho(t, q, p)$ with respect to $d q d p$, which is given by :

$$
\rho(t, q, p) d q d p=\int_{\mathbb{R}^{m}} \int_{\mathbb{R}^{m}} \tau\left(q_{0}, p_{0} ; t ; d q, d p\right) \rho_{Q_{0}, P_{0}}\left(q_{0}, p_{0}\right) d q_{0} d p_{0}
$$

The density $\rho$ satisfies the FKP equation on $\mathbb{R}^{\mathrm{m}} \times \mathbb{R}^{\mathrm{m}}$ :

$$
\frac{\partial}{\partial t} \rho+\sum_{k=1}^{m}\left(\frac{\partial}{\partial q_{k}}\left(\rho b_{k}^{(q)}\right)+\frac{\partial}{\partial p_{k}}\left(\rho b_{k}^{(p)}\right)\right)-\frac{1}{2} \sum_{i, k=1}^{m} \frac{\partial^{2}}{\partial p_{i} \partial p_{k}}\left(\rho[\sigma]_{i k}\right)=0
$$

for $\mathrm{t}>0$, with the initial condition :

$$
\rho(t, q, p) \rightarrow \rho_{Q_{0}, P_{0}}(q, p) \quad \text { as } \quad t \downarrow 0 \text {. }
$$

When all the results hold, we shall say that $(\mathrm{Q}(\mathrm{t}), \mathrm{P}(\mathrm{t}))$ is a regular solution of problem (12)-(2).

\section{(i) - Explicit form of the FKP equation}

Let $u$ and $v$ be two regular functions defined on $\mathbb{R}^{\mathrm{m}} \times \mathbb{R}^{\mathrm{m}}$ with real values. We introduce the Poisson bracket notation :

$$
[\mathrm{u}, \mathrm{v}]=\left\langle\partial_{\mathrm{q}} \mathrm{u}, \partial_{\mathrm{p}} \mathrm{v}\right\rangle-\left\langle\partial_{\mathrm{p}} \mathrm{u}, \partial_{\mathrm{q}} \mathrm{v}\right\rangle
$$

Using (13), (14) and (16), the FKP equation (17) can be written as :

$$
\frac{\partial \rho}{\partial t}+[\rho, H]-\operatorname{div}_{p} L(\rho)=0, t>0
$$

where $\operatorname{div}_{p} L=\sum_{k=1}^{m} \frac{\partial}{\partial p_{k}} L_{k}$, and where $L(\rho)$ is a $\mathbb{R}^{m}$-vector :

$$
L(\rho)=\left(f(H)+\frac{1}{4} h^{\prime}(H)\right) \rho[G] \partial_{p} H+\frac{1}{2} h(H)[G] \partial_{p} \rho
$$

with $\mathrm{h}: \mathbb{R}^{+} \rightarrow \mathbb{R}^{+*}$ the $\mathrm{C}^{1}$-function such that :

$$
h(H)=g^{2}(H)+2 \varepsilon_{m}^{2} \gamma(H)
$$


and $h^{\prime}(H)=d h(H) / d H$. These properties of $h$ result from 2.2, ii-2 and ii-3 .

(ii) Critera for existence and uniqueness of solutions defined up to explosion time

Concerning the critera for the existence and uniqueness of the diffusion process $(\mathrm{Q}(\mathrm{t}), \mathrm{P}(\mathrm{t}))$, solution to problem (12)-(2), in the uniform Lipschitz case, we refer to $[30,31,34]$. But these criteria are not sufficient for the present case and other mathematical tools are necessary.

(ii - 1) Let us suppose the functions $b$ and $[\hat{a}]$ to be continuous on $\mathbb{R}^{\mathrm{m}} \times \mathbb{R}^{\mathrm{m}}$ with the following properties :

(P1) : For all fixed positive real number $\mathrm{R}>0$, and for all $(\mathrm{q}, \mathrm{p})$ and $\left(\mathrm{q}_{0}, \mathrm{p}_{0}\right)$ with $\|q\|^{2}+\|p\|^{2} \leq R^{2}$, $\left\|q_{0}\right\|^{2}+\left\|p_{0}\right\|^{2} \leq R^{2}$, there is a positive constant $K_{R}$ such that :

$$
\begin{gathered}
\left\|b(q, p)-b\left(q_{0}, p_{0}\right)\right\|^{2}+\left\|\hat{a}(q, p)-\hat{a}\left(q_{0}, p_{0}\right)\right\|^{2} \leq K_{R}\left(\left\|q-q_{0}\right\|^{2}+\left\|p-p_{0}\right\|^{2}\right) \\
\|b(q, p)\|^{2}+\|\hat{a}(q, p)\|^{2} \leq K_{R}\left(1+\|q\|^{2}+\|p\|^{2}\right)
\end{gathered}
$$

(P2) : Let $\mathfrak{d}$ be the differential operator on $\mathbb{R}^{\mathrm{m}} \times \mathbb{R}^{\mathrm{m}}$ such that for $\mathrm{u}: \mathbb{R}^{\mathrm{m}} \times \mathbb{R}^{\mathrm{m}} \rightarrow \mathbb{R}$ we have :

$$
\mathfrak{u}_{\mathrm{u}}=\sum_{\mathrm{k}=1}^{\mathrm{m}}\left(\mathrm{b}_{\mathrm{k}}^{(\mathrm{q})} \frac{\partial \mathrm{u}}{\partial \mathrm{q}_{\mathrm{k}}}+\mathrm{b}_{\mathrm{k}}^{(\mathrm{p})} \frac{\partial \mathrm{u}}{\partial \mathrm{p}_{\mathrm{k}}}\right)+\frac{1}{2} \sum_{\mathrm{i}, \mathrm{k}=1}^{\mathrm{m}}[\sigma]_{\mathrm{ik}} \frac{\partial^{2} \mathrm{u}}{\partial \mathrm{p}_{\mathrm{i}} \partial \mathrm{p}_{\mathrm{k}}}
$$

We suppose that there exists a regular function $q, p, t \rightarrow V(q, p, t)$ defined on $\mathbb{R}^{\mathrm{m}} \times \mathbb{R}^{\mathrm{m}} \times \mathbb{R}^{+}$with values in $\mathbb{R}^{+}$, which satisfies the two conditions :

$$
\begin{aligned}
& \exists \lambda>0: \forall(\mathrm{q}, \mathrm{p}, \mathrm{t}), \frac{\partial}{\partial \mathrm{t}} \mathrm{V}(\mathrm{q}, \mathrm{p}, \mathrm{t})+(\text { } \mathrm{v})(\mathrm{q}, \mathrm{p}, \mathrm{t}) \leq \lambda \mathrm{V}(\mathrm{q}, \mathrm{p}, \mathrm{t}) \\
& \operatorname{Inf}_{\|q\|^{2}+\|p\|^{2}>r^{2}, \triangleright 0} \mathrm{~V}(\mathrm{q}, \mathrm{p}, \mathrm{t}) \rightarrow+\infty \quad \text { as } \mathrm{r} \rightarrow+\infty
\end{aligned}
$$

(R1) : With all above assuptions, the stochastic problem (12)-(2) has a unique solution $(\mathrm{Q}(\mathrm{t}), \mathrm{P}(\mathrm{t}))$ which is a $\mathbb{R}^{\mathrm{m}} \times \mathbb{R}^{\mathrm{m}}$-valued diffusive Markov process, a.s continuous, and which does not explode (see $[36,6])$.

(ii-2) Using (13), (14), (16) and (21) we obtain, after calculations :

$$
\mathfrak{W V}=[\mathrm{V}, \mathrm{H}]-\frac{1}{4}\left(4 \mathrm{f}-\mathrm{h}^{\prime}\right)\left\langle[\mathrm{S}]^{\mathrm{T}} \partial_{\mathrm{p}} \mathrm{H},[\mathrm{S}]^{\mathrm{T}} \partial_{\mathrm{p}} \mathrm{V}\right\rangle+\frac{1}{2} \mathrm{~h} \sum_{\mathrm{k}=1}^{\mathrm{m}}\left\langle\left[\partial_{\mathrm{p}}^{2} \mathrm{~V}\right] \mathrm{S}^{\mathrm{k}}, \mathrm{S}^{\mathrm{k}}\right\rangle
$$


where $S^{\mathbf{k}}$ is the $\mathbb{R}^{\mathrm{m}}$-vector such that $S_{\mathrm{j}}^{\mathbf{k}}=[\mathrm{S}]_{\mathrm{jk}}$. Note that in the particular case where $\mathrm{V}=\varphi(\mathrm{H})$, with $\varphi$ a $\mathrm{C}^{2}$-function on $\mathbb{R}$ with real values, relation (24) yields :

$$
\dddot{U V}=\left(\frac{1}{2} \varphi^{\prime \prime} h-\frac{1}{4} \varphi^{\prime}\left(4 \mathrm{f}-\mathrm{h}^{\prime}\right)\right)\left\|[S]^{\mathrm{T}} \partial_{\mathrm{p}} \mathrm{H}\right\|^{2}+\frac{1}{2} \varphi^{\prime} \mathrm{h} \sum_{\mathrm{k}=1}^{\mathrm{m}}\left\langle\left[\partial_{\mathrm{p}}^{2} \mathrm{H}\right] \mathrm{S}^{\mathrm{k}}, \mathrm{S}^{\mathrm{k}}\right\rangle
$$

with $\varphi^{\prime}(\mathrm{H})=\mathrm{d} \varphi(\mathrm{H}) / \mathrm{dH}$. We have used the Poisson bracket property :

$$
[\varphi(\mathrm{H}), \mathrm{H}]=\varphi^{\prime}(\mathrm{H})[\mathrm{H}, \mathrm{H}]=0
$$

(ii-3) For example, we see that the result (R1) holds under the following conditions on $f$ and $\mathrm{h}$ :

$$
\left.\begin{array}{l}
\exists \mathrm{r}_{0}>0, \exists \mathrm{c}_{0}>0 ; \forall \mathrm{r} \geq \mathrm{r}_{0}, \mathrm{~h}(\mathrm{r}) \leq \mathrm{c}_{0} \mathrm{r} \\
\exists \mathrm{r}_{1}>0 ; \forall \mathrm{r} \geq \mathrm{r}_{1}, 4 \mathrm{f}(\mathrm{r})-\mathrm{h}^{\prime}(\mathrm{r}) \geq 0
\end{array}\right\}
$$

The proof is easy to perform. Let us consider the Lyapounov function $\mathrm{V}(\mathrm{q}, \mathrm{p})=\mathrm{H}(\mathrm{q}, \mathrm{p})+\alpha$, independant of $\mathrm{t}$, with $\alpha$ a positive real constant. The condition (23) is satisfied in view of (3). The relation (25) and the inequalities (4) yield :

$$
\mathfrak{X V} \leq-\frac{1}{4}\left(4 \mathrm{f}-\mathrm{h}^{\prime}\right)\left\|[S]^{\mathrm{T}} \partial_{\mathrm{p}} \mathrm{H}\right\|^{2}+\frac{1}{2} \mathrm{~h} \mathrm{C}_{\mathrm{T}}\|\mathrm{S}\| \|^{2}
$$

It is clear that condition (22) is satisfied for all $q$ and $p$ in any closed and bounded subset of $\mathbb{R}^{\mathrm{m}} \times \mathbb{R}^{\mathrm{m}}$. Therefore, in taking into account (3), we can limit the proof of condition (22) to the case $H \geq \sup \left(r_{0}, r_{1}\right)=H_{0}$. For $H \geq H_{0}$, using (27), we get from (28) :

$$
\text { \&V } \leq \lambda \mathrm{V} \text { with } \lambda=\frac{1}{2} \mathrm{C}_{0} \mathrm{C}_{\mathrm{T}}\|\mathrm{S}\|^{2} \text {. }
$$

\subsection{Existence of an asymptotic stationary solution and steady- state FKP equation}

We shall assume that the regular solution $(\mathrm{Q}(\mathrm{t}), \mathrm{P}(\mathrm{t}))$ of problem (12)-(2) tends in probability for $\mathrm{t} \rightarrow+\infty$, to a $\mathbb{R}^{\mathrm{m}} \times \mathbb{R}^{\mathrm{m}}$-valued stationary process $\left(\mathrm{Q}_{S}(\mathrm{t}), \mathrm{P}_{\mathrm{S}}(\mathrm{t})\right)$. Hence we have :

$$
\rho_{S}(q, p)=\lim _{t \rightarrow+\infty} \rho(t, q, p)
$$


where $\rho_{S}(q, p)$ is the probability density function (p.d.f) on $\mathbb{R}^{\mathrm{m}} \times \mathbb{R}^{\mathrm{m}}$ of the random variable $\left(Q_{S}(t), P_{S}(t)\right)$ for any fixed $t$. The steady-state p.d.f $\rho_{S}$ satisfied the steady-state FKP solution associated with (19) :

$$
\left[\rho_{S}, H\right]-\operatorname{div}_{p} L\left(\rho_{S}\right)=0
$$

with the normalization condition :

$$
\int_{\mathbb{R}^{\mathrm{m}}} \int_{\mathbb{R}^{\mathrm{m}}} \rho_{\mathrm{S}}(\mathrm{q}, \mathrm{p}) \mathrm{dq} \mathrm{dp}=1
$$

where $\mathrm{L}$ is given by $(20)$.

\section{Remarks :}

(1) The following result (see ref. [36,30,6]) allows us to check the existence of an asymptotic stationary solution.

If there exists a unique regular solution and in addition there exists another $\mathrm{C}^{2}$-function $\mathrm{q}, \mathrm{p} \rightarrow \mathrm{V}(\mathrm{q}, \mathrm{p})$ on $\mathbb{R}^{\mathrm{m}} \times \mathbb{R}^{\mathrm{m}}$ with values in $\mathbb{R}^{+}$such that :

$$
\operatorname{Sup}_{\|q\|^{2}+\|p\|^{2}}>R^{2}(\mathcal{L V})(\mathrm{q}, \mathrm{p})=-\mathrm{C}_{\mathrm{R}} \quad, \quad \mathrm{C}_{\mathrm{R}} \rightarrow+\infty \text { as } \mathrm{R} \rightarrow+\infty
$$

then a unique asymptotic stationary solution exists.

(2) For example, under all conditions of section 2.2, and if, in addition, the hypotheses (27) on $f$ and $g$ are satisfied, one can prove the existence of the asymptotic stationary solution. The complete proof of this point is lengthly because several cases must be considered and cannot be given here.

\subsection{Exact steady-state p.d.f}

The exact steady-state p.d.f is built by searching the solution of equation (30) in the form $\rho_{S}(q, p)=\varphi(H(q, p))$. Hence, using (26) and (20), we have $\left[\rho_{S}, H\right]=0$ and $\mathcal{L}\left(\rho_{\mathrm{S}}\right)=\psi[\mathrm{G}] \partial_{\mathrm{p}} \mathrm{H}$ with $\psi=\left(\mathrm{f}+\mathrm{h}^{\prime} / 4\right) \varphi+\mathrm{h} \varphi^{\prime} / 2$.

Therefore, equation (30) is verified when $\varphi$ is the solution of equation $\psi=0$, and :

$$
\rho_{S}(q, p)=\frac{C_{m}}{\sqrt{h(H(q, p))}} \exp \left(-2 \int_{0}^{H(q, p)} h(r)^{-1} f(r) d r\right)
$$


where $C_{m}$ is a positive real constant defined by the normalization condition (31), and where $h(H)$ is given by (21).

\section{Remark :}

Conditions (ii) of section 2.2 yield that equation $\partial_{\mathrm{p}} \mathrm{H}(\mathrm{q}, \mathrm{p})=\dot{\mathrm{q}}$ can be solved locally in $p$ for $q$ and $\dot{q}$ in $\mathbb{R}^{m}$. Let $p=A(q, \dot{q}) \in \mathbb{R}^{m}$ be the solution. If we assume that $A$ can be built for all $\mathrm{q}$ and $\dot{\mathrm{q}}$ in $\mathbb{R}^{\mathrm{m}}$ and that $\dot{\mathrm{q}} \rightarrow \mathrm{A}(\mathrm{q}, \dot{\mathrm{q}})$ is a continuouly differentiable $\mathbb{R}^{\mathrm{m}}$-valued function defined on $\mathbb{R}^{\mathrm{m}}$, then the steady-state p.d.f $\rho_{\mathrm{Q}, \dot{\mathrm{Q}}(\mathrm{q}, \dot{\mathrm{q}})}$ of the random variable $\left(\mathrm{Q}_{s}(\mathrm{t}), \mathrm{Q}_{s}(\mathrm{t})\right)$, with respect to dq dq , is given by :

$$
\rho_{Q}, \dot{Q}(q, \dot{q})=\rho_{S}(q, A(q, \dot{q})) \times J_{a}(q, \dot{q})
$$

where $\mathrm{J}_{\mathrm{a}}$ is written as :

$$
\mathrm{J}_{\mathrm{a}}(\mathrm{q}, \dot{\mathrm{q}})=\left|\operatorname{det}\left[\partial_{\dot{\mathrm{q}}} \mathrm{A}(\mathrm{q}, \dot{\mathrm{q}})\right]\right|
$$

with $\left[\partial_{\dot{q}} \mathrm{~A}\right]_{j k}=\frac{\partial A_{j}}{\partial \dot{q}_{k}}$ the Jacobian matrix.

\subsection{Study of the integrability of the steady-state p.d.f}

The integrability of the p.d.f $\rho_{s}$ is not evident to verify when $m>1$. Therefore, we give here after a useful criterion which allows us to study it.

Let $\alpha \geq 0$ be a real constant. Let $\mathrm{M}_{\alpha}$ be the positive number such that :

$$
\mathbf{M}_{\alpha}=\int_{\mathbb{R}^{m}} \int_{\mathbb{R}^{m}}\left(\|q\|^{2}+\|p\|^{2}\right)^{\alpha} \rho_{s}(q, p) d q d p
$$

For $\alpha=0, M_{0}=1$ is the normalization condition. If $\alpha$ is a positive integer, $\mathrm{M}_{\alpha}$ allows to study the existence of the moments of $\rho_{S}$ : For example if $\mathrm{M}_{1}<+\infty$, the random variable $\left(\mathrm{Q}_{\mathrm{S}}(\mathrm{t}), \mathrm{P}_{\mathrm{S}}(\mathrm{t})\right)$ is of second order. Let $\varphi: \mathbb{R}^{+} \rightarrow \mathbb{R}^{+}$be the function :

$$
\varphi(r)=h(r)^{-1 / 2} \exp \left(-2 \int_{0}^{r} h(y)^{-1} f(y) d y\right)
$$


Using relation (33) we can write $\rho_{s}(q, p)=c_{m} \varphi(H(q, p))$ and for any $\alpha \geq 0$ :

$$
\mathrm{M}_{\alpha}=\mathrm{c}_{\mathrm{m}} \mathrm{N}_{\alpha}
$$

where $\mathrm{N}_{\alpha}>0$ is written as :

$$
N_{\alpha}=\int_{\mathbb{R}^{m}} \int_{\mathbb{R}^{m}}\left(\|q\|^{2}+\|p\|^{2}\right)^{\alpha} \varphi(H(q, p)) d q d p
$$

We see that $0<\mathrm{c}_{\mathrm{m}}<+\infty$ if $\mathrm{N}_{0}<+\infty$, because $\mathrm{c}_{\mathrm{m}}=\mathrm{N}_{0}^{-1}$ and $\mathrm{N}_{0}>0$. Consequently we have :

$$
\forall \alpha \geq 0, \mathrm{~N}_{\alpha}<+\infty \Rightarrow \mathrm{M}_{\alpha}<+\infty
$$

because, if $N_{\alpha}<+\infty$, we have $N_{\beta}<+\infty$ for $0 \leq \beta<\alpha$, and in particular,

$$
\mathrm{N}_{\alpha}<+\infty \Rightarrow \mathrm{N}_{0}<+\infty \Rightarrow 0<\mathrm{c}_{\mathrm{m}}<+\infty .
$$

We introduce the following assumption on the $\mathrm{H}$ function, which involves necessarily the property (3):

(i) There exists three real constants : $R_{0} \geq 1, c_{0}>0$ and $\theta>0$ such that

$$
H(q, p) \geq c_{0}\left(\|q\|^{2}+\|p\|^{2}\right)^{\theta}
$$

for any $(\mathrm{q}, \mathrm{p}) \in \mathbb{R}^{\mathrm{m}} \times \mathbb{R}^{\mathrm{m}}$ such that $\|\mathrm{q}\|^{2}+\|\mathrm{p}\|^{2}>\mathrm{R}_{0}^{2}$

We have the following result :

(ii) If assumption (i) is verified and, if for a fixed $\alpha \geq 0$, there exists any positive value of the real constant $\mu \geq 0$, such that :

$$
\lim _{\mathrm{r} \rightarrow+\infty} \mathrm{r}^{(\alpha+\mathrm{m}+\mu) / \theta} \varphi(\mathrm{r})=\mathrm{c}
$$

where $c$ is a real constant such that $0 \leq \mathrm{c}<+\infty$, therefore we have $\mathrm{M}_{\alpha}<+\infty$.

\section{Proof :}

Let $\mathrm{B}_{0}$ be the closed ball of $\mathbb{R}^{\mathrm{m}} \times \mathbb{R}^{\mathrm{m}}$ :

$$
\mathrm{B}_{0}=\left\{\mathrm{q} \in \mathbb{R}^{\mathrm{m}}, \mathrm{p} \in \mathbb{R}^{\mathrm{m}} ;\|\mathrm{q}\|^{2}+\|\mathrm{p}\|^{2} \leq \mathrm{R}_{0}^{2}\right\}
$$


and $U_{0}$ the unbounded open set :

$$
\mathrm{U}_{0}=\left\{\mathrm{q} \in \mathbb{R}^{\mathrm{m}}, \mathrm{p} \in \mathbb{R}^{\mathrm{m}} ;\|\mathrm{q}\|^{2}+\|\mathrm{p}\|^{2}>\mathrm{R}_{0}^{2}\right\} .
$$

One can write $\mathrm{N}_{\alpha}=\mathrm{N}_{\alpha}^{-}+\mathrm{N}_{\alpha}^{+}, \mathrm{N}_{\alpha}^{-}>0, \mathrm{~N}_{\alpha}^{+}>0$, with :

$$
\mathrm{N}_{\alpha}^{-}=\iint_{\mathrm{B}_{0}} \mathrm{~J}(\mathrm{q}, \mathrm{p}) \mathrm{dq} d \mathrm{p} \quad ; \quad \mathrm{N}_{\alpha}^{+}=\iint_{\mathrm{U}_{0}} \mathrm{~J}(\mathrm{q}, \mathrm{p}) \mathrm{dq} \mathrm{dp}
$$

and $J(q, p)=\left(\|q\|^{2}+\|p\|^{2}\right)^{\alpha} \varphi(H(q, p))$.

For any $\alpha \geq 0$, we have $0<\mathrm{N}_{\alpha}^{-}<+\infty$ because $\mathrm{J}$ is a continuous function on the closed ball $\mathrm{B}_{0}$. For any real $\mu>0$, we can write the inequalities $0<\mathrm{N}_{\alpha}^{+}<\mathrm{I}_{0} \times \mathrm{I}_{1}$ where :

(1) $I_{0}$ is the finite positive real number :

$$
I_{0}=\iint_{U_{0}} \frac{d q d p}{\left(\|q\|^{2}+\|p\|^{2}\right)^{m+\mu}}=\frac{S_{2 m}}{2 \mu R_{0}^{2 \mu}}<+\infty
$$

where $S_{2 m}=2 \pi^{m} / \Gamma(m)$ is the area of the unit sphere in $\mathbb{R}^{2 m}$ and where $\Gamma$ denotes the gamma function.

(2) $I_{1}$ is the positive number such that :

$$
I_{1}=\operatorname{Sup}_{(q, p) \in U_{0}}\left\{\left(\left\|q_{0}\right\|^{2}+\left\|p_{0}\right\|^{2}\right)^{\alpha+m+\mu} \varphi(H(q, p))\right\} .
$$

In using (40), we see that $\mathrm{I}_{1}<+\infty$ if the condition (41) is verified.

\section{Example}

Let us consider the very simple case : functions $f, g$ and $h$ are such that $f(r)=f_{0}$, $g(r)=g_{0}, h(r)=g_{0}^{2}+2 \varepsilon_{m}^{2} r$ with $f_{0}$ and $g_{0}$ two positive real constants. The Hamiltonian function is written as $\mathrm{H}=\frac{1}{2}\left\langle[\mathrm{M}]^{-1} \mathrm{p}, \mathrm{p}\right\rangle+\frac{1}{2}\langle[\mathrm{~K}] \mathrm{q}, \mathrm{q}\rangle$ where $[\mathrm{M}]$ and $[\mathrm{K}]$ are two $(\mathrm{m} \times \mathrm{m})$ real symmetric and positive-definite matrices. The calculation of (36) yields :

$$
\varphi(r)=\left(g_{0}^{2}+2 \varepsilon_{m}^{2} r\right)^{-\left(\frac{1}{2}+\frac{\varepsilon_{0}}{\varepsilon_{m}^{2}}\right)}
$$


In using the criterion (41) with $\theta=1$ et $c>0$, we obtain $\mu=-\alpha-m+\frac{1}{2}+f_{0} / \varepsilon_{m}^{2}$. The condition $\mu>0$ yields $M_{\alpha}<+\infty$ if $\alpha+m<\frac{1}{2}+\frac{f_{0}}{\varepsilon_{m}^{2}}$. We see that a second order solution is obtained if the dimension $m$ of the discrete dynamical system is such that $m<f_{0} / \varepsilon_{m}^{2}-1 / 2$.

\subsection{Examples of multi-dimensional nonlinear oscillators under external random excitations}

In this section we give some examples of multi-dimensional nonlinear oscillators under external random excitations only .

(i) Example 1 : General case

The canonical equations (1) - (5) are written in this case $\left(\varepsilon_{\mathrm{m}}=0\right)$ :

$$
\left\{\begin{array}{l}
\dot{Q}=\partial_{p} H(Q, P) \\
\dot{P}=-\partial_{q} H(Q, P)-f(H)[G] \dot{Q}+g(H)[S] \eta(t)
\end{array}\right.
$$

and the function $h$, defined by $(21)$, is such that $h=g^{2}$. Note that the parametric excitation vanishes completely if $\mathrm{g}$ is a constant function. Using the remark of section 2.6 , we have :

$$
\dot{\mathrm{q}}=\partial_{\mathrm{p}} \mathrm{H}(\mathrm{q}, \mathrm{p}) \quad ; \quad \mathrm{p}=\mathrm{A}(\mathrm{q}, \mathrm{q}) \in \mathbb{R}^{\mathrm{m}}
$$

Let $\mathbb{H}(\mathrm{q}, \dot{\mathrm{q}})$ be the real-valued function on $\mathbb{R}^{\mathrm{m}} \times \mathbb{R}^{\mathrm{m}}$ such that :

$$
\mathbb{H}(\mathrm{q}, \dot{\mathrm{q}})=\mathrm{H}(\mathrm{q}, \mathrm{A}(\mathrm{q}, \dot{\mathrm{q}}))
$$

and $\mathbb{F}(\mathrm{q}, \dot{\mathrm{q}})$ be the $\mathbb{R}^{\mathrm{m}}$-valued function defined on $\mathbb{R}^{\mathrm{m}} \times \mathbb{R}^{\mathrm{m}}$ such that :

$$
\mathbb{F}(\mathrm{q}, \mathrm{q})=\mathfrak{F}(\mathrm{q}, \mathrm{A}(\mathrm{q}, \dot{\mathrm{q}})) ; \quad \mathfrak{F}(\mathrm{q}, \mathrm{p})=\partial_{\mathrm{q}} \mathrm{H}(\mathrm{q}, \mathrm{p})
$$

With these notations, the canonical form (43) is equivalent to the following second order nonlinear differential equation on $\mathbb{R}^{\mathrm{m}}$ :

$$
\frac{\mathrm{d}}{\mathrm{dt}} \mathrm{A}(\mathrm{Q}, \dot{\mathrm{Q}})+\mathrm{f}(\mathbb{H})[\mathrm{G}] \dot{\mathrm{Q}}+\mathbb{F}(\mathrm{Q}, \dot{\mathrm{Q}})=\mathrm{g}(\mathbb{H})[\mathrm{S}] \eta(\mathrm{t})
$$


For this multi-dimensional nonlinear oscillator (47), we have the expression (33) for the p.d.f of the random variable $\left(\mathrm{Q}_{s}(\mathrm{t}), \mathrm{P}_{S}(\mathrm{t})\right)$ :

$$
\rho_{s}(q, p)=\frac{C_{m}}{g(H(q, p))} \exp \left(-2 \int_{0}^{H(q, p)} g(r)^{-2} f(r) d r\right)
$$

and (34) for the r.v $\left(\mathrm{Q}_{s}(\mathrm{t}), \dot{\mathrm{Q}}_{\mathrm{s}}(\mathrm{t})\right)$ :

$$
\rho_{\mathrm{Q}, \dot{\mathrm{Q}}}(\mathrm{q}, \dot{\mathrm{q}})=\frac{\mathrm{C}_{\mathrm{m}}^{\prime} \mathrm{J}_{\mathrm{a}}(\mathrm{q}, \dot{\mathrm{q}})}{\mathrm{g}(\mathbb{H}(\mathrm{q}, \dot{\mathrm{q}}))} \exp \left(-2 \int_{0}^{\mathbb{H}(\mathrm{q}, \dot{\mathrm{q}})} \mathrm{g}(\mathrm{r})^{-2} \mathrm{f}(\mathrm{r}) \mathrm{dr}\right)
$$

with $\mathrm{J}_{\mathrm{a}}$ given by (34).

(ii) Example 2 : Particular nonlinear dynamical systems

Let $[M(q)]$ be a symmetric real $(\mathrm{m} \times \mathrm{m})$ matrix such that for all $\mathrm{q}$ in $\mathbb{R}^{\mathrm{m}},[\mathrm{M}(\mathrm{q})]$ is positive-definite, and $\mathrm{q} \rightarrow[\mathrm{M}(\mathrm{q})]^{-1}$ is a $\mathrm{C}^{2}$-function bounded on $\mathbb{R}^{\mathrm{m}}$. We assume that the kinetic energy of the dynamical system is written as :

$$
\mathrm{T}(\mathrm{q}, \dot{\mathrm{q}})=\frac{1}{2}\langle[\mathrm{M}(\mathrm{q})] \dot{\mathrm{q}}, \dot{\mathrm{q}}\rangle
$$

In this case, the generalized impulsion $p=\partial_{\dot{q}} T$ is given by :

$$
\mathrm{p}=[\mathrm{M}(\mathrm{q})] \dot{\mathrm{q}} \doteq \mathrm{A}(\mathrm{q}, \dot{\mathrm{q}})
$$

Let $\psi$ (q) be the $C^{2}$-potential function on $\mathbb{R}^{\mathrm{m}}$. Therefore, the Hamiltonian function is such that :

$$
H(q, p)=\frac{1}{2}\left\langle[M(q)]^{-1} p, p\right\rangle+\psi(q)
$$

The relation (45) yields :

$$
\mathbb{H}(\mathrm{q}, \dot{\mathrm{q}})=\frac{1}{2}\langle[\mathrm{M}(\mathrm{q})] \dot{\mathrm{q}}, \dot{\mathrm{q}}\rangle+\psi(\mathrm{q})
$$

and the equation (47) of this nonlinear oscillator is :

$$
\frac{d}{d t}([M(Q)] \dot{Q})+f(\mathbb{H})[G] \dot{Q}+\partial_{q} \psi(Q)=g(\mathbb{H})[S] \eta(t)
$$

The steady-state p.d.f is given by (48) or by (49) with $\mathrm{J}_{\mathrm{a}}(\mathrm{q}, \dot{\mathrm{q}})=|\operatorname{det}[\mathrm{M}(\mathrm{q})]|$.

We can apply this result to obtain the following multi-dimensional cases. 
Let $[M]$ and $[K]$ be two symmetric real $(\mathrm{m} \times \mathrm{m})$ positive-definite matrices ; Let $\mathrm{f}_{0}$ and $\mathrm{g}_{0}$ be two positive real constants and $\alpha_{0}=\frac{\mathrm{f}_{0}}{\mathrm{~g}_{0}{ }^{2}}$. Let $\mathrm{H}$ and $\mathbb{H}$ be such that :

$$
\begin{gathered}
H(q, p)=\frac{1}{2}\left\langle[M]^{-1} p, p\right\rangle+\frac{1}{2}\langle[K] q, q\rangle \\
\mathbb{H}(q, \dot{q})=\frac{1}{2}\langle[M] \dot{q}, \dot{q}\rangle+\frac{1}{2}\langle[K] q, q\rangle
\end{gathered}
$$

- For the linear oscillator :

$$
[\mathrm{M}] \ddot{\mathrm{Q}}+\mathrm{f}_{0}[\mathrm{G}] \dot{\mathrm{Q}}+[\mathrm{K}] \mathrm{Q}=\mathrm{g}_{0}[\mathrm{~S}] \eta(\mathrm{t})
$$

we have the gaussian case :

$$
\rho_{\mathrm{Q}, \dot{\mathrm{Q}}}(\mathrm{q}, \dot{\mathrm{q}})=\mathrm{C}_{\mathrm{m}}^{\prime} \exp \left\{-2 \alpha_{0} \mathbb{H}(\mathrm{q}, \dot{\mathrm{q}})\right\}
$$

with $\mathbb{H}$ given by (56) .

- For the nonlinear damping :

$$
[\mathrm{M}] \ddot{\mathrm{Q}}+\mathrm{f}(\mathbb{H})[\mathrm{G}] \dot{\mathrm{Q}}+[\mathrm{K}] \mathrm{Q}=\mathrm{g}_{0}[\mathrm{~S}] \eta(\mathrm{t})
$$

with $\mathbb{H}$ given by (56) and $f$ by :

$$
\mathrm{f}(\mathbb{H})=-\mathrm{f}_{0}(1-\langle[\mathrm{M}] \mathrm{Q}, \dot{\mathrm{Q}}\rangle-\langle[\mathrm{K}] \mathrm{Q}, \mathrm{Q}\rangle)
$$

we have :

$$
\rho_{\mathrm{Q}, \dot{\mathrm{Q}}}(\mathrm{q}, \dot{\mathrm{q}})=\mathrm{C}_{\mathrm{m}}^{\prime} \exp \left\{2 \alpha_{0} \mathbb{H}(1-\mathbb{H})\right\}
$$

- For the cubic restoring force case, the potential function on $\mathbb{R}^{\mathrm{m}}$ is defined by :

$$
\psi(q)=\frac{1}{2} T_{0}\langle[K] q, q\rangle+\frac{1}{4} T_{1}\langle[K] q, q\rangle^{2}
$$

where $T_{0}$ and $T_{1}$ are two positive real constants. The equation is :

$$
[\mathrm{M}] \mathrm{Q}+\mathrm{f}_{0}[\mathrm{G}] \dot{\mathrm{Q}}+\left(\mathrm{T}_{0}+\mathrm{T}_{1}\langle[\mathrm{~K}] \mathrm{Q}, \mathrm{Q}\rangle\right)[\mathrm{K}] \mathrm{Q}=\mathrm{g}_{0}[\mathrm{~S}] \eta(\mathrm{t})
$$

and we obtain :

$$
\rho_{\mathrm{Q}, \dot{\mathrm{Q}}}(\mathrm{q}, \dot{\mathrm{q}})=C_{\mathrm{m}}^{\prime} \exp \left\{-2 \alpha_{0} \mathbb{H}(\mathrm{q}, \dot{\mathrm{q}})\right\}
$$

with $\mathbb{H}$ given by $(53)$ - (60) with $[M(q)]=[M]$. 


\section{(iii) Example 3 : Extension of example 2}

We can generalize example 2 by considering a more general form of the kinetic energy (50) of the dynamical systems :

$$
\mathrm{T}(\mathrm{q}, \dot{\mathrm{q}})=\frac{1}{2}\langle[\mathrm{M}(\mathrm{q})] \dot{\mathrm{q}}, \dot{\mathrm{q}}\rangle+\langle\mathrm{B}(\mathrm{q}), \dot{\mathrm{q}}\rangle+\mathrm{C}(\mathrm{q})
$$

such that $\mathrm{T}(\mathrm{q}, \dot{\mathrm{q}}) \geq 0$ for all $\mathrm{q}$ and $\dot{\mathrm{q}}$ in $\mathbb{R}^{\mathrm{m}},[\mathrm{M}(\mathrm{q})]$ as in example $2, \mathrm{~B}(\mathrm{q}) \in \mathbb{R}^{\mathrm{m}}$, $\mathrm{C}(\mathrm{q}) \in \mathbb{R}$. In this case the generalized impulsion $\mathrm{p}=\partial_{\dot{\mathrm{q}}} \mathrm{T}$ is written as :

$$
\mathrm{p}=[\mathrm{M}(\mathrm{q})] \dot{\mathrm{q}}+\mathrm{B}(\mathrm{q}) \doteq \mathrm{A}(\mathrm{q}, \dot{\mathrm{q}})
$$

The Hamiltonian function is defined by

$$
H(q, p)=\frac{1}{2}\left\langle[M(q)]^{-1}(p-B(q), p-B(q)\rangle+2\left\langle[M(q)]^{-1}(p-B(q), B(q)\rangle+C(q)+\psi(q)\right.\right.
$$

and relation (45) yields :

$$
\mathbb{H}(\mathrm{q}, \dot{\mathrm{q}})=\frac{1}{2}\langle[\mathrm{M}(\mathrm{q})] \dot{\mathrm{q}}, \dot{\mathrm{q}}\rangle+2\langle\mathrm{~B}(\mathrm{q}), \dot{\mathrm{q}}\rangle+\mathrm{C}(\mathrm{q})+\psi(\mathrm{q})
$$

\subsection{Examples of multi-dimensional nonlinear oscillators under parametric and external random excitations}

In using relations (44) to (46), we can write the second order nonlinear differential equation on $\mathbb{R}^{\mathrm{m}}$, equivalent to the canonical form (1) - (5)

$$
\frac{\mathrm{d}}{\mathrm{dt}} \mathrm{A}(\mathrm{Q}, \dot{\mathrm{Q}})+\mathrm{f}(\mathbb{H})[\mathrm{G}] \dot{\mathrm{Q}}+\mathbb{F}(\mathrm{Q}, \dot{\mathrm{Q}})+\varepsilon_{\mathrm{m}} \sum_{\mathrm{j}=1}^{\mathrm{J}}[\mathrm{S}]\left[\xi_{j}(\mathrm{t})\right] \mathbb{U}^{(\mathrm{j})}(\mathrm{Q}, \dot{\mathrm{Q}})=\mathrm{g}(\mathbb{H})[\mathrm{S}] \eta(\mathrm{t})
$$

which is the equation (47) with additional parametric random excitations. For this multidimensional nonlinear oscillator under parametric and external random excitations, the exact steady-state p.d.f $\rho_{S}$ is given by (33) and p.d.f $\rho_{Q}, \dot{Q}$ by (34) - (35) . 


\section{(i) Example 4 : Nonlinear oscillator with linear conservative part}

We consider the linear and nonlinear dynamical systems with linear associated conservative part.

Let $[\mathrm{M}]$ and $[\mathrm{K}]$ be two symmetric real $(\mathrm{m} \times \mathrm{m})$ positive-definite matrices. The functions $\mathrm{H}$ and $\mathbb{H}$ are given respectively by (55) and (56). Let $r \rightarrow k(r)$ be a $C^{1}$-function on $\mathbb{R}^{+}$with values in $\mathbb{R}^{+}$. Taking $\mathrm{J}=2$ and defining the $\mathbb{U}^{(\mathrm{j})}$ functions by :

$$
\mathbb{U}^{(1)}(\mathrm{q}, \dot{\mathrm{q}})=\mathrm{k}(\mathbb{H})[M]^{1 / 2} \dot{\mathrm{q}} ; \quad \mathbb{U}^{(2)}(\mathrm{q}, \dot{\mathrm{q}})=\mathrm{k}(\mathbb{H})[\mathrm{K}]^{1 / 2} \mathrm{q}
$$

we obtain :

$$
\mathrm{U}^{(1)}(\mathrm{q}, \mathrm{p})=\mathrm{k}(\mathrm{H})[\mathrm{M}]^{-1 / 2} \mathrm{p} ; \mathrm{U}^{(2)}(\mathrm{q}, \mathrm{p})=\mathrm{k}(\mathrm{H})[\mathrm{K}]^{1 / 2} \mathrm{q}
$$

Relations (6) and (21) yield the expression of the function $\mathrm{h}$ :

$$
h(r)=g^{2}(r)+2 \varepsilon_{m}^{2} r k^{2}(r)
$$

In these conditions the equation (62) is written as :

$$
\begin{aligned}
& {[\mathrm{M}] \ddot{\mathrm{Q}}+\left\{\mathrm{f}(\mathbb{H})[\mathrm{G}]+\varepsilon_{\mathrm{m}} \mathrm{k}(\mathbb{H})[\mathrm{S}]\left[\xi_{1}(\mathrm{t})\right][\mathrm{M}]^{1 / 2}\right\} \dot{\mathrm{Q}}} \\
& +\left\{[\mathrm{K}]+\varepsilon_{\mathrm{m}} \mathrm{k}(\mathbb{H})[\mathrm{S}]\left[\xi_{2}(\mathrm{t})\right][\mathrm{K}]^{1 / 2}\right\} \mathrm{Q}=\mathrm{g}(\mathbb{H})[\mathrm{S}] \eta(\mathrm{t})
\end{aligned}
$$

and the exact steady-state p.d.f is given by :

$$
\rho_{S}(q, p)=C_{m} \varphi(H(q, p))
$$

or by :

$$
\rho_{\mathrm{Q}, \dot{\mathrm{Q}}}(\mathrm{q}, \mathrm{p})=\mathrm{C}_{\mathrm{m}}^{\prime} \varphi(\mathbb{H}(\mathrm{q}, \dot{\mathrm{q}}))
$$

with :

$$
\varphi(r)=h(r)^{-1 / 2} \exp \left(-2 \int_{0}^{r} f(y) h(y)^{-1} d y\right)
$$

We have $A(q, q)=[M] \dot{q}$ and consequently, $\mathrm{J}_{\mathrm{a}}$ defined by (35), is a constant.

Note that if we have the relation :

$$
f(r)=\alpha_{0} h(r)-\frac{1}{4} h^{\prime}(r)
$$


with $\alpha_{0}$ a positive real constant, and where $h^{\prime}(r)=d h(r) / d r$ we obtain :

$$
\varphi(r)=\exp \left(-2 \alpha_{0} r\right)
$$

and $\rho_{S}$ ( resp. $\left.\rho_{Q}, \dot{Q}\right)$ is a gaussian p.d.f in taking into account (65)-(55), ( resp.(66)-(56)). As shown in ref. [18] on the example of an particular one dimensional nonlinear oscillator, we can obtain for the multi-dimensional oscillator (64) under a suitable combination of the parametric and external gaussian excitations, a gaussian steady-state p.d.f for the random $\operatorname{variable}\left(\mathrm{Q}_{\mathrm{s}}(\mathrm{t}), \mathrm{P}_{\mathrm{S}}(\mathrm{t})\right)$.

- We can apply the results (64) to (67) to obtain the extension of (57) and (58) with parametric random excitations. Let $f_{0}$ and $g_{0}$ be two positive real constants.

- For the linear oscillator with parametric excitations :

$$
\begin{aligned}
& {[\mathrm{M}] \ddot{\mathrm{Q}}+\left\{\mathrm{f}_{0}[\mathrm{G}]+\varepsilon_{\mathrm{m}}[\mathrm{S}]\left[\xi_{1}(\mathrm{t})\right][\mathrm{M}]^{1 / 2}\right\} \dot{\mathrm{Q}}} \\
& +\left\{[\mathrm{K}]+\varepsilon_{\mathrm{m}}[\mathrm{S}]\left[\xi_{2}(\mathrm{t})\right][\mathrm{K}]^{1 / 2}\right\} \mathrm{Q}=\mathrm{g}_{0}[\mathrm{~S}] \eta(\mathrm{t})
\end{aligned}
$$

the steady-state p.d.f, given by (65) - (67), is written as :

$$
\rho_{S}(q, p)=C_{m}\left(g_{0}^{2}+2 \varepsilon_{m}^{2} H(q, p)\right)^{-\left(\frac{1}{2}+\frac{f_{0}}{\varepsilon_{m}^{2}}\right)}
$$

with $\mathrm{H}$ given by (55).

In using the result of the example of section 2.7 , we see that the r.v $\left(Q_{s}(t), P_{S}(t)\right)$ is of second order if $\mathrm{m}, \mathrm{f}_{0}$ and $\varepsilon_{\mathrm{m}}$ verify the inequality : $\mathrm{m}<\mathrm{f}_{0} / \varepsilon_{\mathrm{m}}^{2}-1 / 2$. The steady-state p.d.f $\rho_{\mathrm{Q}, \dot{\mathrm{Q}}}(\mathrm{q}, \dot{\mathrm{q}})$ is given by the right hand side of $(69)$ in replacing $\mathrm{H}(\mathrm{q}, \mathrm{p})$ by $\mathbb{H}(\mathrm{q}, \dot{\mathrm{q}})$ given by (56) .

- For the nonlinear damping with parametric excitations :

$$
\begin{array}{r}
{[\mathrm{M}] \ddot{\mathrm{Q}}+\left\{\mathrm{f}_{0}(\langle[\mathrm{M}] \dot{\mathrm{Q}}, \dot{\mathrm{Q}}\rangle+\langle[\mathrm{K}] \mathrm{Q}, \mathrm{Q}\rangle-1)[\mathrm{G}]+\varepsilon_{\mathrm{m}}[\mathrm{S}]\left[\xi_{1}(\mathrm{t})\right][\mathrm{M}]^{1 / 2}\right\} \dot{\mathrm{Q}}} \\
+\left\{[\mathrm{K}]+\varepsilon_{\mathrm{m}}[\mathrm{S}]\left[\xi_{2}(\mathrm{t})\right][\mathrm{K}]^{1 / 2}\right\} \mathrm{Q}=\mathrm{g}_{0}(\mathbb{H})[\mathrm{S}] \eta(\mathrm{t})
\end{array}
$$

the steady-state p.d.f is written as :

$$
\rho_{s}(\mathrm{q}, \mathrm{p})=\mathrm{C}_{\mathrm{m}}\left(\mathrm{g}_{0}^{2}+2 \varepsilon_{\mathrm{m}}^{2} \mathrm{H}(\mathrm{q}, \mathrm{p})\right)^{\frac{\mathrm{f}_{0}}{\varepsilon_{\mathrm{m}}^{2}}\left(1+\frac{\mathrm{g} \mathrm{g}^{2}}{\varepsilon_{\mathrm{m}}^{2}}\right)-\frac{1}{2}} \times \exp \left(-\frac{2 \mathrm{f}_{0}}{\varepsilon_{\mathrm{m}}^{2}} \mathrm{H}(\mathrm{q}, \mathrm{p})\right)
$$


In using the criterion (41), we see that all the moments of the r.v $\left(Q_{S}(t), P_{S}(t)\right)$ have finite values . Conformably to the preceding result, we have a gaussian steady-state p.d.f, for this nonlinear dynamical system, if the constants $\mathrm{f}_{0}, \mathrm{~g}_{0}$ and $\varepsilon_{\mathrm{m}}$ verify the equality :

$$
\frac{f_{0}}{\varepsilon_{m}^{2}}\left(1+\frac{g_{0}^{2}}{\varepsilon_{m}^{2}}\right)=\frac{1}{2}
$$

(ii) Example 5 : Nonlinear oscillator with nonlinear conservative part

Let be $\mathrm{H}(\mathrm{q}, \mathrm{p})$ the Hamiltonian function defined by $(52)$ of the nonlinear dynamical system of example 2 . Let $\mathrm{k}$ be the function defined in example 4 , and $[\mathrm{K}]$ be a symmetric real $(\mathrm{m} \times \mathrm{m})$ positive-definite matrix related to a normalization of the potential function $\psi$. Taking $\mathrm{J}=2$ and defining :

$$
\begin{aligned}
& \mathbb{U}^{(1)}(\mathrm{q}, \dot{\mathrm{q}})=\mathrm{k}(\mathbb{H})[\mathrm{M}(\mathrm{q})]^{1 / 2} \dot{\mathrm{q}} \\
& \mathbb{U}^{(2)}(\mathrm{q}, \dot{\mathrm{q}})=\mathrm{k}(\mathbb{H}) \sqrt{2 \psi(\mathrm{q})\langle[\mathrm{K}] \mathrm{q}, \mathrm{q}\rangle^{-1}}[\mathrm{~K}]^{1 / 2} \mathrm{q}
\end{aligned}
$$

the equation (62) is written as :

$$
\begin{aligned}
& \frac{\mathrm{d}}{\mathrm{dt}}([\mathrm{M}(\mathrm{Q})] \dot{\mathrm{Q}})+\left(\mathrm{f}(\mathbb{H})[\mathrm{G}]+\varepsilon_{\mathrm{m}} \mathrm{k}(\mathbb{H})[\mathrm{S}]\left[\xi_{1}(\mathrm{t})\right][\mathrm{M}(\mathrm{Q})]^{1 / 2}\right) \dot{\mathrm{Q}} \\
& +\partial_{\mathrm{q}} \psi(\mathrm{Q})+\varepsilon_{\mathrm{m}} \mathrm{k}(\mathbb{H}) \sqrt{2 \psi(\mathrm{O})\langle[\mathrm{K}] \mathrm{Q}, \mathrm{Q}\rangle^{-1}}[\mathrm{~S}]\left[\xi_{2}(\mathrm{t})\right][\mathrm{K}]^{1 / 2} \mathrm{Q} \\
& =\mathrm{g}(\mathbb{H})[\mathrm{S}] \eta(\mathrm{t})
\end{aligned}
$$

with $\mathbb{H}$ the function defined by (53).

The exact steady-state p.d.f $\rho_{S}(q, p)$ is given by (33) with $h$ defined by (63) and $H$ by (52) . -We can deduce the cubic restoring force case (61) with parametric excitations. The potential function is given by (60). The equation is :

$$
\begin{aligned}
& {[\mathrm{M}] \ddot{\mathrm{Q}}+\left(\mathrm{f}_{0}[\mathrm{G}]+\varepsilon_{\mathrm{m}}[\mathrm{S}]\left[\xi_{1}(\mathrm{t})\right][\mathrm{M}]^{1 / 2}\right) \dot{\mathrm{Q}}} \\
& +\left\{\left(\mathrm{T}_{0}+\mathrm{T}_{1}\langle[\mathrm{~K}] \mathrm{Q}, \mathrm{Q}\rangle\right)[\mathrm{K}]+\varepsilon_{\mathrm{m}} \sqrt{\mathrm{T}_{0}+\frac{1}{2} \mathrm{~T}_{1}\langle[\mathrm{~K}] \mathrm{Q}, \mathrm{Q}\rangle}[\mathrm{S}]\left[\xi_{2}(\mathrm{t})\right][\mathrm{K}]^{1 / 2}\right\} \mathrm{Q} \\
& =\mathrm{g}_{0}[\mathrm{~S}] \eta(\mathrm{t})
\end{aligned}
$$

with $\mathrm{f}_{0}>0$ and $\mathrm{g}_{0}>0$. The exact steady-state p.d.f $\rho_{\mathrm{S}}(\mathrm{q}, \mathrm{p})$ is given by (69) with $\mathrm{H}$ defined by $(52)-(60)$ in taking $[M(q)]=[M]$. 


\section{Complements for the radial Hamiltonain case}

In this section, we give some complements for the case where Hamiltonian function $\mathrm{H}$ has a radial form.

The radial case concerns the class of nonlinear oscillator with linear conservative part and also a large class of nonlinear conservative parts. There is a great interest for studying this case, because all the multiple integrals on $\mathbb{R}^{\mathrm{m}} \times \mathbb{R}^{\mathrm{m}}$ can be explicitly calculated for any finite dimension $\mathrm{m}$, to obtain the normalization condition, the characteristic function and the covariance operator.

\subsection{Definiton of a class of radial Hamiltonian functions}

In all this section 3, we shall consider the nonlinear stochastic differential equation (1)(5) and we shall suppose that all the assumptions of sections 2.2 to 2.6 are verified. Hence, the steady-state p.d.f $\rho_{s}(q, p)$ is given by relation (33).

Let $[\mathrm{M}]$ and $[\mathrm{K}]$ be two positive-definite symmetric real $(\mathrm{m} \times \mathrm{m})$ matrices. Therefore, the bilinear mappings $\dot{\mathrm{q}}_{1}, \dot{\mathrm{q}}_{2} \rightarrow\left\langle[\mathrm{M}] \dot{\mathrm{q}}_{1}, \dot{\mathrm{q}}_{2}\right\rangle$ and $\mathrm{q}_{1}, \mathrm{q}_{2} \rightarrow\left\langle[\mathrm{K}] \mathrm{q}_{1}, \mathrm{q}_{2}\right\rangle$ are inner products on $\mathbb{R}^{\mathrm{m}}$, and we can write :

$$
\left.\begin{array}{c}
\mathrm{u}=[\mathrm{K}]^{1 / 2} \mathrm{q} ;\langle[\mathrm{K}] \mathrm{q}, \mathrm{q}\rangle=\left\langle[\mathrm{K}]^{1 / 2} \mathrm{q},[\mathrm{K}]^{1 / 2} \mathrm{q}\right\rangle=\|\mathrm{u}\|^{2} \\
\mathrm{v}=[\mathrm{M}]^{1 / 2} \dot{\mathrm{q}} ;\langle[\mathrm{M}] \dot{\mathrm{q}}, \dot{\mathrm{q}}\rangle=\left\langle[\mathrm{M}]^{1 / 2} \dot{\mathrm{q}},[\mathrm{M}]^{1 / 2} \dot{\mathrm{q}}\right\rangle=\|\mathrm{v}\|^{2}
\end{array}\right\}
$$

The radial form of the Hamiltonian function $\mathrm{H}$ is defined by

$$
H(q, p)=\frac{1}{2}\left\langle[M]^{-1} p, p\right\rangle+\dot{\Lambda}\left(\frac{1}{2}\langle[K] q, q\rangle\right)
$$

where $r \rightarrow \Lambda(r)$ can be any mapping from $\mathbb{R}^{+}$to $\mathbb{R}^{+}$such that all assumptions on $H$ introduced in section 2.2 be verified.

The generalized impulsion is written as : $\mathrm{p}=[\mathrm{M}] \dot{\mathrm{q}} \doteq \mathrm{A}(\mathrm{q}, \dot{\mathrm{q}})$ and the steady-state p.d.f $\rho_{\mathrm{Q}, \dot{Q}}$ on $\mathbb{R}^{\mathrm{m}} \times \mathbb{R}^{\mathrm{m}}$ is given by (34) - (35):

$$
\rho_{\mathrm{Q}, \dot{\mathrm{Q}}}(\mathrm{q}, \dot{\mathrm{q}})=\frac{\mathrm{C}_{\mathrm{m}}}{\sqrt{\mathrm{h}(\mathbb{H}(\mathrm{q}, \dot{\mathrm{q}}))}} \exp \left(-2 \int_{0}^{\mathbb{H}(\mathrm{q}, \dot{\mathrm{q}})} \mathrm{h}(\mathrm{r})^{-1} \mathrm{f}(\mathrm{r}) \mathrm{dr}\right)
$$


where $\mathrm{C}_{\mathrm{m}}$ is the positive real constant defined by the normalization condition :

$$
\int_{\mathbb{R}^{\mathrm{m}}} \int_{\mathbb{R}^{\mathrm{m}}} \rho_{\mathrm{Q}, \dot{\mathrm{Q}}}(\mathrm{q}, \dot{\mathrm{q}}) \mathrm{dq} \mathrm{dq}=1
$$

The function $\mathrm{r} \rightarrow \mathrm{h}(\mathrm{r}): \mathbb{R}^{+} \rightarrow \mathbb{R}^{+}$is given by (21):

$$
h(r)=g^{2}(r)+2 \varepsilon_{m}^{2} \gamma(r)
$$

and function $\mathbb{H}: \mathbb{R}^{\mathrm{m}} \times \mathbb{R}^{\mathrm{m}} \rightarrow \mathbb{R}^{+}$is defined by (45) :

$$
\mathbb{H}(\mathrm{q}, \dot{\mathrm{q}})=\frac{1}{2}\langle[\mathrm{M}] \dot{\mathrm{q}}, \dot{\mathrm{q}}\rangle+\Lambda\left(\frac{1}{2}\langle[\mathrm{~K}] \mathrm{q}, \mathrm{q}\rangle\right)
$$

\subsection{Explicit form of the steady-state p.d.f}

Let $r_{1}, r_{2} \rightarrow H_{0}\left(r_{1}, r_{2}\right)$ and $r_{1}, r_{2} \rightarrow \mu\left(r_{1}, r_{2}\right)$ be two functions from $\mathbb{R}^{+} \times \mathbb{R}^{+}$to $\mathbb{R}^{+}$such that :

$$
\begin{gathered}
\mathrm{H}_{0}\left(\mathrm{r}_{1}, \mathrm{r}_{2}\right)=\Lambda\left(\frac{1}{2} \mathrm{r}_{1}^{2}\right)+\frac{1}{2} \mathrm{r}_{2}^{2} \\
\mu\left(\mathrm{r}_{1}, \mathrm{r}_{2}\right)=\frac{1}{\sqrt{\mathrm{h}\left(\mathrm{H}_{0}\left(\mathrm{r}_{1}, \mathrm{r}_{2}\right)\right)}} \exp \left(-2 \int_{0}^{\mathrm{H}_{0}\left(\mathrm{r}_{1}, \mathrm{r}_{2}\right)} \mathrm{h}(\mathrm{y})^{-1} \mathrm{f}(\mathrm{y}) \mathrm{dy}\right)
\end{gathered}
$$

Therefore, we have :

$$
\begin{gathered}
\mathbb{H}(\mathrm{q}, \dot{\mathrm{q}})=\mathrm{H}_{0}\left(\langle[\mathrm{~K}] \mathrm{q}, \mathrm{q}\rangle^{1 / 2},\langle[\mathrm{M}] \dot{\mathrm{q}}, \dot{\mathrm{q}}\rangle^{1 / 2}\right) \\
\rho_{\mathrm{Q}, \dot{\mathrm{Q}}}(\mathrm{q}, \dot{\mathrm{q}}) \mathrm{dq} \mathrm{d} \dot{\mathrm{q}}=\sqrt{\operatorname{det}[\mathrm{MK}]} \frac{\Gamma^{2}(\mathrm{~m} / 2)}{4 \pi^{\mathrm{m}}} \frac{\mu\left(\langle[\mathrm{K}] \mathrm{q}, \mathrm{q}\rangle^{1 / 2},\langle[\mathrm{M}] \dot{\mathrm{q}}, \dot{\mathrm{q}}\rangle^{1 / 2}\right) d \mathrm{q} \dot{\mathrm{q}}}{\int_{0}^{+\infty} \int_{0}^{+\infty} \mathrm{r}_{1}^{\mathrm{m}-1} \mathrm{r}_{2}^{\mathrm{m}-1} \mu\left(\mathrm{r}_{1}, \mathrm{r}_{2}\right) d r_{1} \mathrm{dr} r_{2}}
\end{gathered}
$$

where $\Gamma(z)=\int_{0}^{+\infty} t^{z-1} e^{-t} d t$ is the gamma function. 
Proof :

(a) Let $\mathrm{x} \rightarrow \mathrm{s}(\mathrm{x}): \mathbb{R}^{\mathrm{m}} \rightarrow \mathbb{R}$ be a function that depends only on $\mathrm{r}=\|\mathrm{x}\|$. We denote such a function $\mathrm{s}(\mathrm{x})=\mathrm{S}(\|\mathrm{x}\|)$ with $\mathrm{r} \rightarrow \mathrm{S}(\mathrm{r}): \mathbb{R}^{+} \rightarrow \mathbb{R}$. We have :

$$
\int_{\mathbb{R}^{m}} s(x) d x=\frac{2 \pi^{m / 2}}{\Gamma(m / 2)} \int_{0}^{+\infty} S(r) r^{m-1} d r
$$

(b) The equalities (79) and (80) yield (82).

(c) Taking into account (81) and (82), the p.d.f $\rho_{\mathrm{Q}, \mathrm{Q}}$ given by (76) is written as :

$$
\rho_{\mathrm{Q}, \dot{Q}}(\mathrm{q}, \dot{\mathrm{q}}) \mathrm{dq} \mathrm{d} \dot{\mathrm{q}}=\mathrm{C}_{\mathrm{m}} \mu\left(\langle[\mathrm{K}] \mathrm{q}, \mathrm{q}\rangle^{1 / 2},\langle[\mathrm{M}] \dot{\mathrm{q}}, \dot{\mathrm{q}})^{1 / 2}\right) \mathrm{dq} \mathrm{d} \dot{\mathrm{q}}
$$

The normalization condition (77) yields :

$$
\mathrm{C}_{\mathrm{m}}^{-1}=\int_{\mathbb{R}^{\mathrm{m}}} \int_{\mathbb{R}^{\mathrm{m}}} \mu\left(\langle[\mathrm{K}] \mathrm{q}, \mathrm{q}\rangle^{1 / 2},\langle[\mathrm{M}] \dot{\mathrm{q}}, \dot{\mathrm{q}}\rangle^{1 / 2}\right) \mathrm{dq} \dot{\mathrm{q}}
$$

Using (74) and applying the theorem on integration with respect to the measure image, we can also write

$$
\mathrm{C}_{\mathrm{m}}^{-1}=(\operatorname{det}[\mathrm{MK}])^{-1 / 2} \int_{\mathbb{R}^{\mathrm{m}}} \int_{\mathbb{R}^{\mathrm{m}}} \mu(\|\mathrm{ull},\| \mathrm{v} \|) \mathrm{du} \mathrm{dv}
$$

We obtain (83) in using (84) and by substitution in (85).

\subsection{Moment of total energy}

Let $\varepsilon_{S}(t)=\mathbb{H}\left(Q_{S}(t), \dot{Q}_{S}(t)\right)$ be the $\mathbb{R}^{+}$-valued random variable at any fixed time $t$, related to the dynamical system in its steady-state. The moment of order $j$ of the r.v $\varepsilon_{S}(t)$ is written as :

$$
E\left(\varepsilon_{S}(t)^{j}\right)=\int_{\mathbb{R}^{m}} \int_{\mathbb{R}^{m}} \mathbb{H}(q, \dot{q})^{j} \rho_{Q, \dot{Q}}(q, \dot{q}) d q d \dot{q}
$$


For fixed $\mathrm{j}$, the moment can be infinite. Using (74), (83) and (84), we obtain :

$$
E\left(\varepsilon_{S}(t)^{j}\right)=\frac{\int_{0}^{+\infty} \int_{0}^{+\infty} H_{0}\left(r_{1}, r_{2}\right)^{j} r_{1}^{m-1} r_{2}^{m-1} \mu\left(r_{1}, r_{2}\right) d r_{1} d r_{2}}{\int_{0}^{+\infty} \int_{0}^{+\infty} r_{1}^{m-1} r_{2}^{m-1} \mu\left(r_{1}, r_{2}\right) d r_{1} d r_{2}}
$$

\subsection{Charasteristic function}

For every fixed $t$, the characteristic function of the $\mathbb{R}^{\mathrm{m}} \times \mathbb{R}^{\mathrm{m}}$-valued random variable $\left(\mathrm{Q}_{s}(\mathrm{t}), \dot{\mathrm{Q}}_{S}(\mathrm{t})\right)$ is the mapping $\alpha, \beta \rightarrow \hat{\mathrm{P}}_{\mathrm{Q}, \dot{\mathrm{Q}}}(\alpha, \beta)$ from $\mathbb{R}^{\mathrm{m}} \times \mathbb{R}^{\mathrm{m}}$ to $\mathbb{C}$ which is defined by :

$$
\begin{aligned}
\hat{\rho}_{\mathrm{Q}, \dot{\mathrm{Q}}}(\alpha, \beta) & =\mathrm{E}\left\{\exp \left(\mathrm{i}\left\langle\alpha, \mathrm{Q}_{\mathrm{S}}(\mathrm{t})\right\rangle+\mathrm{i}\left\langle\beta, \dot{\mathrm{Q}}_{\mathrm{S}}(\mathrm{t})\right\rangle\right)\right\} \\
& =\int_{\mathbb{R}^{\mathrm{m}}} \int_{\mathbb{R}^{\mathrm{m}}} \mathrm{e}^{\mathrm{i}\langle\alpha, \mathrm{q}\rangle+\mathrm{i}\langle\beta, \dot{\mathrm{q}}\rangle \rho_{\mathrm{Q}, \dot{\mathrm{Q}}}(\mathrm{q}, \dot{\mathrm{q}}) d \mathrm{~d} d \dot{\mathrm{q}}}
\end{aligned}
$$

With the preceding assumptions, $\hat{\rho}_{\mathrm{Q}, \mathrm{Q}}$ is a real valued function on $\mathbb{R}^{\mathrm{m}} \times \mathbb{R}^{\mathrm{m}}$ which is written as :

$$
\hat{\rho}_{\mathrm{Q}, \dot{Q}}(\alpha, \beta)=\Phi\left(\left\langle[\mathrm{K}]^{-1} \alpha, \alpha\right\rangle^{1 / 2},\left\langle[\mathrm{M}]^{-1} \beta, \beta\right\rangle^{1 / 2}\right)
$$

with $R_{1}, R_{2} \rightarrow \Phi\left(R_{1}, R_{2}\right)$ the real valued function on $\mathbb{R} \times \mathbb{R}$ such that :

$$
\Phi\left(R_{1}, R_{2}\right)=\left[\begin{array}{ll}
2^{v} & \Gamma(v+1)
\end{array}\right]^{2} D_{v}^{-1} N_{v}\left(R_{1}, R_{2}\right)
$$

with :

$$
\begin{gathered}
v=\frac{\mathrm{m}}{2}-1 \\
\mathrm{D}_{v}=\int_{0}^{+\infty} \int_{0}^{+\infty} \mathrm{r}_{1}^{2 v+1} \mathrm{r}_{2}^{2 v+1} \mu\left(\mathrm{r}_{1}, \mathrm{r}_{2}\right) \mathrm{dr}_{1} \mathrm{dr}_{2}
\end{gathered}
$$




$$
N_{v}\left(R_{1}, R_{2}\right)=\int_{0}^{+\infty} \int_{0}^{+\infty} r_{1}^{2 v+1} r_{2}^{2 v+1} \frac{J_{v}\left(r_{1} R_{1}\right)}{\left(r_{1} R_{1}\right)^{v}} \frac{J_{v}\left(r_{2} R_{2}\right)}{\left(r_{2} R_{2}\right)^{v}} \mu\left(r_{1}, r_{2}\right) d r_{1} d r_{2}
$$

and where $J_{v}$ is the Bessel function :

$$
J_{v}(x)=\frac{(x / 2)^{v}}{\sqrt{\pi} \Gamma(v+1 / 2)} \int_{-1}^{1}\left(1-t^{2}\right)^{(v-1 / 2)} \cos t x d t
$$

Proof :

(a) Let be $\mathrm{x} \rightarrow \mathrm{s}(\mathrm{x})=\mathrm{S}(\|\mathrm{x}\|): \mathbb{R}^{\mathrm{m}} \rightarrow \mathbb{C}, \mathrm{r} \rightarrow \mathrm{s}(\mathrm{r}): \mathbb{R}^{+} \rightarrow \mathbb{C}$. If $\mathrm{s} \in \mathrm{L}^{1}\left(\mathbb{R}^{\mathrm{m}}, \mathbb{C}\right)$ (integrable function), the Fourrier transform $\hat{s}$ (y) is defined for any $y$ in $\mathbb{R}^{\mathrm{m}}$ by :

$$
\hat{\mathbf{s}}(\mathbf{y})=\hat{S}(\|y\|)=\int_{\mathbb{R}^{\mathrm{m}}} \mathrm{e}^{-i|x, y\rangle S(\|x\|) d x}
$$

with $R \rightarrow \widehat{S}(R): \mathbb{R}^{+} \rightarrow \mathbb{C}$ the function such that :

$$
\widehat{S}(R)=2 \pi\left(\frac{2 \pi}{R}\right)^{\frac{m}{2}-1} \int_{0}^{+\infty} r^{m / 2} \frac{J_{\frac{m}{2}-1}}{2}(r R) S(r) d r
$$

(b) Using (74) - (83), and because $[\mathrm{K}]^{-1 / 2}$ and $[\mathrm{M}]^{-1 / 2}$ are two symmetric real matrices, function $\hat{\rho}_{\mathrm{Q}, \mathrm{Q}}$ which is given by (87), can be written as :

$$
\hat{\rho}_{\mathrm{Q}, \dot{Q}}(\alpha, \beta)=\frac{\Gamma^{2}(\mathrm{~m} / 2) \int_{\mathbb{R}^{\mathrm{m}}} \int_{\mathbb{R}^{\mathrm{m}}} \mu(\|\mathrm{ull},\| \mathrm{v} \|) \exp \left\{\mathrm{i}\left\langle[\mathrm{K}]^{-1 / 2} \alpha, \mathrm{u}\right\rangle+\mathrm{i}\left\langle[\mathrm{M}]^{-1 / 2} \beta, \mathrm{v}\right\rangle\right\} \mathrm{du} d \mathrm{v}}{4 \pi^{\mathrm{m}} \int_{0}^{+\infty} \int_{0}^{+\infty} \mathrm{r}_{1}^{\mathrm{m}-1} \mathrm{r}_{2}^{\mathrm{m}-1} \mu\left(\mathrm{r}_{1}, \mathrm{r}_{2}\right) d r_{1} d r_{2}}
$$

Because $\mu$ is a $\mathbb{R}^{+}$-valued function, we can conjuguate the equality (93) and we obtain (88) - (89), using formula (93) - (94) for the $u$ and $v$ variables. 
Remark 1 concerning the marginal laws :

Let us note that $v \neq-1,-2, \ldots$, and then we have :

$$
\frac{J_{v}(x)}{x^{v}} \rightarrow \frac{1}{2^{v} \Gamma(v+1)} \text { if } x \rightarrow 0
$$

Hence we deduce from equality (89), that :

$$
\begin{aligned}
& \Phi\left(R_{1}, 0\right)=2^{v} \Gamma(v+1) D_{v}^{-1} \int_{0}^{+\infty} \int_{0}^{+\infty} r_{1}^{2 v+1} r_{2}^{2 v+1} \frac{J_{v}\left(r_{1} R_{1}\right)}{\left(r_{1} R_{1}\right)^{v}} \mu\left(r_{1}, r_{2}\right) d r_{1} d r_{2} \\
& \Phi\left(0, R_{2}\right)=2^{v} \Gamma(v+1) D_{v}^{-1} \int_{0}^{+\infty} \int_{0}^{+\infty} r_{1}^{2 v+1} r_{2}^{2 v+1} \frac{J_{v}\left(r_{2} R_{2}\right)}{\left(r_{2} R_{2}\right)^{v}} \mu\left(r_{1}, r_{2}\right) d r_{1} d r_{2}
\end{aligned}
$$

Remark 2 concerning the derivatives of the characteristic function :

We have the formula :

$$
\frac{d}{d x}\left(\frac{J_{v}(x)}{x^{v}}\right)=-\frac{J_{v+1}(x)}{x^{v}}
$$

Using (95), (98), and also the relation $\Gamma(z+1)=z \Gamma(z)$, one can calculate the following partial derivatives of $\Phi$ at point $R_{1}=R_{2}=0$ :

$$
\begin{aligned}
& \frac{\partial \Phi}{\partial R_{1}}(0,0)=\frac{\partial \Phi}{\partial R_{2}}(0,0)=0 \\
& \frac{\partial^{2} \Phi}{\partial R_{1} \partial R_{2}}(0,0)=0 \\
& \frac{\partial^{2} \Phi}{\partial R_{1}^{2}}(0,0)=-\frac{1}{2(v+1)} D_{v}^{-1} \int_{0}^{+\infty} \int_{0}^{+\infty} r_{1}^{2 v+3} r_{2}^{2 v+1} \mu\left(r_{1}, r_{2}\right) d r_{1} d r_{2}
\end{aligned}
$$




$$
\frac{\partial^{2} \Phi}{\partial R_{2}^{2}}(0,0)=-\frac{1}{2(v+1)} D_{v}^{-1} \int_{0}^{+\infty} \int_{0}^{+\infty} r_{1}^{2 v+1} r_{2}^{2 v+3} \mu\left(r_{1}, r_{2}\right) d r_{1} d r_{2}
$$

We shall use these relations in the next section.

Remark 3 concerning the numerical calculations of the characteristic function

Let us introduce the following notations :

$$
\begin{aligned}
& y\left(z, z^{\prime}\right)=\frac{1}{\Gamma(z) \Gamma\left(z^{\prime}\right)} \int_{0}^{+\infty} \int_{0}^{+\infty} r_{1}^{2 z-1} r_{2}^{2 z^{\prime}-1} \mu\left(r_{1}, r_{2}\right) d r_{1} d r_{2} \\
& a_{k k^{\prime}}=\frac{y\left(v+1+k, v+1+k^{\prime}\right)}{y(v+1, v+1)}
\end{aligned}
$$

Hence, the function $\Phi$, defined by (89) can be calculated by the series :

$$
\Phi\left(R_{1}, R_{2}\right)=\sum_{k=0}^{+\infty} \sum_{k^{\prime}=0}^{+\infty} \frac{1}{k ! k^{\prime} !}\left(-\frac{1}{4} R_{1}^{2}\right)^{k^{k}}\left(-\frac{1}{4} R_{2}^{2}\right)^{k^{\prime}} a_{k k^{\prime}}
$$

The result (105) is proved by substituting into the right-hand side of (92), the ascending series of the Bessel function :

$$
J_{v}(z)=\left(\frac{1}{2} z\right)^{v} \sum_{k=0}^{+\infty} \frac{\left(-\frac{1}{4} z^{2}\right)^{k}}{k ! \Gamma(v+k+1)}
$$

\subsection{Covariance operator}

In this section we shall consider the $\mathbb{R}^{\mathrm{m}} \times \mathbb{R}^{\mathrm{m}}$-valued random variable $\left(\mathrm{Q}_{s}(\mathrm{t}), \dot{\mathrm{Q}}_{s}(\mathrm{t})\right)$ for any fixed $t$. We shall assume that this random variable is of second order.

Let $\theta$ and $\dot{\theta}$ be two positive real variables. Relations (87) and (88) yield :

$$
E\left\{\exp \left(i \theta\left\langle\alpha, Q_{s}(t)\right\rangle+i \dot{\theta}\left\langle\alpha, \dot{Q}_{s}(t)\right\rangle\right)\right\}=\Phi\left(\theta\left\langle[K]^{-1} \alpha, \alpha\right\rangle^{1 / 2}, \dot{\theta}\left\langle[M]^{-1} \beta, \beta\right)^{1 / 2}\right)
$$


In taking the partial derivatives with respect to $\theta$ and $\dot{\theta}$ and for $\theta$ and $\dot{\theta} \rightarrow 0_{+}$, we obtain for all $\alpha$ and $\beta$ in $\mathbb{R}^{\mathrm{m}}$ :

$$
\begin{aligned}
& E\left(\left\langle\alpha, Q_{s}(t)\right\rangle\right)=-i\left\langle[K]^{-1} \alpha, \alpha\right\rangle^{1 / 2} \frac{\partial \Phi}{\partial R_{1}}(0,0) \\
& E\left(\left\langle\beta, \dot{Q}_{S}(t)\right\rangle\right)=-i\left\langle[M]^{-1} \beta, \beta\right\rangle^{1 / 2} \frac{\partial \Phi}{\partial R_{2}}(0,0) \\
& E\left(\left\langle\alpha, Q_{S}(t)\right\rangle\left\langle\beta, \dot{Q}_{S}(t)\right\rangle\right)=-\left\langle[K]^{-1} \alpha, \alpha\right\rangle^{1 / 2}\left\langle[M]^{-1} \beta, \beta\right\rangle^{1 / 2} \frac{\partial^{2} \Phi}{\partial R_{1} \partial R_{2}}(0,0) \\
& E\left(\left\langle\alpha, Q_{S}(t)\right\rangle^{2}\right)=-\left\langle[K]^{-1} \alpha, \alpha\right\rangle \frac{\partial^{2} \Phi}{\partial R_{1}{ }^{2}}(0,0) \\
& E\left(\left\langle\beta, \dot{Q}_{S}(t)\right\rangle^{2}\right)=-\left\langle[M]^{-1} \beta, \beta\right\rangle \frac{\partial^{2} \Phi}{\partial R_{2}{ }^{2}}(0,0)
\end{aligned}
$$

(i) Taking into account the relations (99), (107) and (108), we see that the random variable $\left(\mathrm{Q}_{s}(\mathrm{t}), \dot{\mathrm{Q}}_{\mathrm{s}}(\mathrm{t})\right)$ is centered.

(ii) In these conditions, the covariance matrix $\left[\mathrm{C}_{S}\right] \in \mathrm{Mat}(2 \mathrm{~m}, 2 \mathrm{~m})$ of the r.v $\left(\mathrm{Q}_{s}(\mathrm{t}), \mathrm{Q}_{\mathrm{s}}(\mathrm{t})\right)$ can be written as :

$$
\left[C_{S}\right]=\left[\begin{array}{ll}
C_{Q Q} & C_{Q \dot{Q}} \\
C_{\dot{Q Q}} & C_{\dot{Q Q}}
\end{array}\right]
$$

where:

$$
\left[\mathrm{C}_{\mathrm{QQ}}\right]=\mathrm{E}\left[\mathrm{Q}_{\mathrm{S}}(\mathrm{t}) \mathrm{Q}_{\mathrm{S}}(\mathrm{t})^{\mathrm{T}}\right] ;\left[\mathrm{C}_{\dot{\mathrm{Q}} \dot{\mathrm{Q}}}\right]=\mathrm{E}\left[\dot{\mathrm{Q}}_{\mathrm{s}}(\mathrm{t}) \dot{\mathrm{Q}}_{\mathrm{S}}(\mathrm{t})^{\mathrm{T}}\right]
$$

are two symmetric positive real $(\mathrm{m} \times \mathrm{m})$ matrices which can be defined by the quadratic forms on $\mathbb{R}^{\mathrm{m}}$ :

$$
\begin{aligned}
& \alpha \rightarrow\left\langle\left[\mathrm{C}_{\mathrm{Q} Q}\right] \alpha, \alpha\right\rangle=\mathrm{E}\left(\left\langle\alpha, \mathrm{Q}_{\mathrm{s}}(\mathrm{t})\right\rangle^{2}\right) \\
& \beta \rightarrow\left\langle\left[\mathrm{C}_{\dot{\mathrm{Q}} \dot{\mathrm{Q}}}\right] \beta, \beta\right\rangle=\mathrm{E}\left(\left\langle\beta, \dot{\mathrm{Q}}_{\mathrm{S}}(\mathrm{t})\right\rangle^{2}\right)
\end{aligned}
$$

and where

$$
\left[\mathrm{C}_{\mathrm{Q}}\right]=\mathrm{E}\left[\mathrm{Q}_{S}(\mathrm{t}) \dot{\mathrm{Q}}_{\mathrm{S}}(\mathrm{t})^{\mathrm{T}}\right] ;\left[\mathrm{C}_{\dot{\mathrm{Q}}}\right]=\mathrm{E}\left[\dot{\mathrm{Q}}_{\mathrm{S}}(\mathrm{t}) \mathrm{Q}_{S}(\mathrm{t})^{\mathrm{T}}\right]
$$


are two real $(\mathrm{m} \times \mathrm{m})$ matrices such that :

$$
\left[\mathrm{C}_{\dot{Q} \mathrm{O}}\right]=\left[\mathrm{C}_{\mathrm{QQ}}\right]^{\mathrm{T}}
$$

the matrix $\left[\mathrm{C}_{\mathrm{Q}}\right]$ beeing defined by the bilinear form on $\mathbb{R}^{\mathrm{m}} \times \mathbb{R}^{\mathrm{m}}$ :

$$
\alpha, \beta \rightarrow\left\langle\left[\mathrm{C}_{\mathrm{Q} \dot{\mathrm{Q}}}\right] \beta, \alpha\right\rangle=\mathrm{E}\left(\left\langle\alpha, \mathrm{Q}_{s}(\mathrm{t})\right\rangle\left\langle\beta, \dot{\mathrm{Q}}_{s}(\mathrm{t})\right\rangle\right)
$$

Using the relations (100) to (102), (109) to (111) and (113) to (118) we obtain the following results :

$$
\begin{aligned}
& {\left[\mathrm{C}_{\mathrm{Q} \dot{Q}}\right]=\left[\mathrm{C}_{\dot{Q}}\right]=[0]} \\
& {\left[\mathrm{C}_{\mathrm{QQ}}\right]=\mathcal{Z}_{\mathrm{m}}[\mathrm{K}]^{-1}} \\
& {\left[\mathrm{C}_{\dot{\mathrm{Q}}}\right]=\dot{\mathrm{Z}}_{\mathrm{m}}[\mathrm{M}]^{-1}}
\end{aligned}
$$

with :

$$
\mathcal{Z}_{\mathrm{m}}=\frac{1}{\mathrm{~m}} \frac{\mathrm{X}(\mathrm{m}+1, \mathrm{~m}-1)}{\mathrm{X}(\mathrm{m}-1, \mathrm{~m}-1)} \quad ; \quad \dot{\boldsymbol{Z}}_{\mathrm{m}}=\frac{1}{\mathrm{~m}} \frac{\mathrm{X}(\mathrm{m}-1, \mathrm{~m}+1)}{\mathrm{X}(\mathrm{m}-1, \mathrm{~m}-1)}
$$

and where $\mathrm{X}(\mathrm{p}, \mathrm{q})$ is written as :

$$
X(p, q)=\int_{0}^{+\infty} \int_{0}^{+\infty} r_{1}^{p} r_{2}^{q} \mu\left(r_{1}, r_{2}\right) d r_{1} d r_{2}
$$

\section{Remark}

The $\left(\mathrm{Q}_{s}, \dot{\mathrm{Q}}_{\mathrm{S}}\right)$ stochastic process being stationary, we know that $\left[\mathrm{C}_{\dot{Q} \mathrm{O}}\right]+\left[\mathrm{C}_{\mathrm{Q}}\right]=[0]$. Taking into account the general property (113), we get :

$$
\left[\mathrm{C}_{\mathrm{Q}}\right]^{\mathrm{T}}=-\left[\mathrm{C}_{\mathrm{Q}}\right]
$$

Therefore, $\left[\mathrm{C}_{\mathrm{Q}}\right]$ is an antisymmetric matrix. But, relation (124) gives (119) only when $m=1$. For the multi-dimensional case $m>1$, result (119) is not a general property for the second order vector-valued stochastic processes. 


\subsection{Examples}

(i) Example 6 : linear oscillator under external random excitations

We can use the gaussian stationary response of the linear oscillator (57) to check the formulas established in sections 3.1 to 3.6 .

For this oscillator, $\mathbb{H}$ is given by (56), therefore $\Lambda(r)=r, H_{0}\left(r_{1}, r_{2}\right)=\frac{1}{2}\left(r_{1}^{2}+r_{2}^{2}\right)$ and $\mu\left(r_{1}, r_{2}\right)=g_{0}^{-1} \exp \left(-\alpha_{0}\left(r_{1}^{2}+r_{2}^{2}\right)\right)$ with $\alpha_{0}=f_{0} g_{0}^{-2}$.

(a) Using the formula :

$$
\int_{0}^{+\infty} r^{n-1} e^{-\alpha_{0} r^{2}} d r=\frac{\Gamma(n / 2)}{2 \alpha_{0}^{n / 2}}
$$

one can calculate (83) and we obtain :

$$
\rho_{\mathrm{Q}, \dot{\mathrm{Q}}}(\mathrm{q}, \dot{\mathrm{q}})=\left(\frac{\alpha_{0}}{\pi}\right)^{\mathrm{m}} \sqrt{\operatorname{det}[\mathrm{MK}]} \exp \left\{-\alpha_{0}(\langle[\mathrm{~K}] \mathrm{q}, \mathrm{q}\rangle+\langle[\mathrm{M}] \dot{\mathrm{q}}, \dot{\mathrm{q}}\rangle)\right\}
$$

(b) Using always (125), the calculation of (104) gives $\boldsymbol{Q}_{\mathrm{kk}}=\alpha_{0}^{-\left(\mathrm{k}+\mathrm{k}^{\prime}\right)}$.

In applying (105) and in using the summation of the series $\sum_{\mathrm{k}=0}^{+\infty}(\mathrm{k} !)^{-1} \mathrm{x}^{\mathrm{k}}=\exp (\mathrm{x})$, we get $\Phi\left(R_{1}, R_{2}\right)=\exp \left(-\left(4 \alpha_{0}\right)^{-1}\left(R_{1}{ }^{2}+R_{2}{ }^{2}\right)\right)$. Finally, we deduce from (88) the gaussian characteristic function :

$$
\hat{\rho}_{\mathrm{Q}, \dot{\mathrm{Q}}}(\alpha, \beta)=\exp \left\{-\frac{1}{4 \alpha_{0}}\left(\left\langle[\mathrm{~K}]^{-1} \alpha, \alpha\right\rangle+\left\langle[\mathrm{M}]^{-1} \beta, \beta\right\rangle\right)\right\}
$$

(c) Using $\Gamma(\mathrm{z}+1)=\mathrm{z} \Gamma(\mathrm{z})$ and (125), the relations (122) give $\mathcal{Z}_{\mathrm{m}}=\dot{\boldsymbol{Z}}_{\mathrm{m}}=\left(2 \alpha_{0}\right)^{-1}$. Thus, we deduce from (120) - (121) :

$$
\left[\mathrm{C}_{\mathrm{QQ}}\right]=\frac{1}{2 \alpha_{0}}[\mathrm{~K}]^{-1} \quad ; \quad\left[\mathrm{C}_{\dot{\mathrm{Q}}}\right]=\frac{1}{2 \alpha_{0}}[\mathrm{M}]^{-1}
$$


(ii) Example 7 : Linear conservative part with nonlinear damping under external random excitations

Let us consider the nonlinear oscillator (58) - (59). Functions $\Lambda$ and $\mathrm{H}_{0}$ are as in the example 6, and we have $\mu\left(\mathrm{r}_{1}, \mathrm{r}_{2}\right)=\mathrm{g}_{0}{ }^{-1} \exp \left\{2 \alpha_{0} \mathrm{H}_{0}\left(1-\mathrm{H}_{0}\right)\right\}$

We introduce the two special functions [37]:

$$
\begin{aligned}
& \int_{0}^{\pi / 2} \sin \mu-1 \theta \cos ^{\mathrm{v}-1} \theta d \theta=\frac{1}{2} B\left(\frac{\mu}{2}, \frac{v}{2}\right) \\
& \int_{0}^{+\infty} \mathrm{e}^{-\mathrm{xR}-\frac{1}{2} \mathrm{R}^{2}} \mathrm{R}^{\mathrm{a}-1 / 2} \mathrm{dR}=\mathrm{e}^{\mathrm{x}^{2 / 4}} \Gamma\left(\mathrm{a}+\frac{1}{2}\right) \mathrm{U}(\mathrm{a}, \mathrm{x})
\end{aligned}
$$

where :

$$
B(x, y)=B(y, x)=\frac{\Gamma(x) \Gamma(x)}{\Gamma(x+y)}=2 \int_{0}^{+\infty} \frac{t^{2 x-1}}{\left(1+t^{2}\right)^{x+y}} d t
$$

is the Beta function (Euler's integral of the first kind), and where $U(a, x)$ is the parabolic cylinder function. We can calculate $\mathrm{X}(\mathrm{p}, \mathrm{q})$ defined by (123), using the polar coordinates $r_{1}=r \cos \theta, r_{2}=r \sin \theta$, and the relations (129) - (131). We get :

$$
X(p, q)=\frac{1}{2 g_{0}} \frac{\Gamma\left(\frac{q+1}{2}\right) \Gamma\left(\frac{p+1}{2}\right)}{\Gamma\left(\frac{p+q+2}{2}\right)} \int_{0}^{+\infty} r^{p+q+1} \exp \left(\alpha_{0} r^{2}-\frac{\alpha_{0}}{2} r^{4}\right) d r
$$

The above integral can be calculated with the transformation $\alpha_{0} \mathrm{r}^{4}=\mathrm{R}^{4}$ and using (130). One has:

$$
X(p, q)=\frac{e^{\alpha_{0} / 4}}{4 g_{0}} \frac{\Gamma\left(\frac{q+1}{2}\right) \Gamma\left(\frac{p+1}{2}\right)}{\left(\sqrt{\alpha_{0}}\right)^{\frac{p+q+2}{2}}} U\left(\frac{p+q+1}{2},-\sqrt{\alpha_{0}}\right)
$$


(a) Starting from (132) with $\mathrm{p}=\mathrm{q}=\mathrm{m}-1$, we deduce from (83) the steady-state p.d.f :

$$
\rho_{\mathrm{QQ}}(\mathrm{q}, \dot{\mathrm{q}})=\frac{\sqrt{\operatorname{det}[\mathrm{MK}]}}{\mathrm{U}\left(\mathrm{m}-\frac{1}{2},-\sqrt{\alpha_{0}}\right)}\left(\frac{\sqrt{\alpha_{0}}}{\pi}\right)^{\mathrm{m}} \mathrm{e}^{-\alpha_{0} / 4} \exp \left(2 \alpha_{0} \mathbb{H}(1-\mathbb{H})\right)
$$

with $\mathbb{H}$ given by (56).

(b) The covariance matrices are given by relations (119) to (121). Using (132), relations (122) yield :

$$
z_{\mathrm{m}}=\dot{z}_{\mathrm{m}}=\frac{1}{2 \sqrt{\alpha_{0}}} \frac{\mathrm{U}\left(\mathrm{m}+\frac{1}{2},-\sqrt{\alpha_{0}}\right)}{\mathrm{U}\left(\mathrm{m}-\frac{1}{2},-\sqrt{\alpha_{0}}\right)}
$$

(c) It is interesting to determine the asymptotic behaviour of $\mathcal{Z}_{\mathrm{m}}$ when $\mathrm{m}$ tends towards infinity. For fixed $x, a>0$, we have [37] :

$$
\begin{aligned}
& U(a, x)=\frac{\sqrt{\pi} 2^{-\frac{a}{2}-\frac{1}{4}}}{\Gamma\left(\frac{3}{4}+\frac{a}{2}\right)} e^{-\sqrt{a} x+v_{1}(a)} \\
& v_{1}(a) \sim \frac{1}{\sqrt{a}} \quad \text { if } a \rightarrow+\infty
\end{aligned}
$$

On the other hand, we have for $z \rightarrow+\infty$ :

$$
\frac{\Gamma(z)}{\Gamma\left(z+\frac{1}{2}\right)} \sim z^{-1 / 2}
$$

Using (135) and (136), the relation (134) yields :

$$
\mathrm{m} \rightarrow+\infty \quad, \quad Z_{\mathrm{m}}=\dot{Z}_{\mathrm{m}} \sim \frac{1}{2 \sqrt{\alpha_{0}}} \frac{1}{\sqrt{\mathrm{m}+1}} \exp \left(\frac{1}{8} \sqrt{\frac{\alpha_{0}}{\mathrm{~m}}}\right)
$$

(d) Characteristic function can be performed in using (105). See for instance the following example 8 . 
(iii) Example 8 : Nonlinear cubic restoring force under random external excitations

We consider now the nonlinear oscillator (60) - (61). The function $\mathbb{H}$ is given by (79) with $\Lambda(r)=T_{0} r+T_{1} r^{2}$. In these conditions, we have $\mu\left(r_{1}, r_{2}\right)=\mu_{1}\left(r_{1}\right) \times \mu_{2}\left(r_{2}\right)$ with: $\mu_{1}\left(r_{1}\right)=\exp \left(-\alpha_{0} T_{0} r_{1}^{2}-\frac{1}{2} \alpha_{0} T_{1} r_{1}^{4}\right) ; \mu_{2}\left(r_{2}\right)=g_{0}{ }^{-1} \exp \left(-\alpha_{0} r_{2}^{2}\right)$

where $\alpha_{0}=\mathrm{f}_{0} \mathrm{~g}_{0}{ }^{-2}$. In this case, $\mathrm{X}(\mathrm{p}, \mathrm{q})$ defined by (124), is written as :

$$
\begin{aligned}
& X(p, q)=X_{1}(p) X_{2}(q) \\
& X_{1}(p)=\frac{\Gamma\left(\frac{p+1}{2}\right)}{2\left(\sqrt{\alpha_{0} T_{1}} \frac{p+1}{2}\right.} U\left(\frac{p}{2}, \gamma\right) e^{\gamma^{2 / 4}} \\
& X_{2}(q)=g_{0}-1 \frac{\Gamma\left(\frac{q+1}{2}\right)}{2 \alpha_{0} \frac{q+1}{2}} \\
& \gamma=\sqrt{\alpha_{0}} \frac{T_{0}}{\sqrt{T_{1}}}
\end{aligned}
$$

(a) The steady-state p.d.f (83) is written as :

$$
\rho_{\mathrm{QQ}}(\mathrm{q}, \dot{\mathrm{q}})=\frac{\sqrt{\operatorname{det}[\mathrm{MK}]}}{\mathrm{U}\left(\frac{\mathrm{m}-1}{2}, \gamma\right)}\left(\frac{\alpha_{0}^{3} \mathrm{~T}_{1}}{\pi^{4}}\right)^{\mathrm{m} / 4} \mathrm{e}^{-\gamma^{2} / 4} \exp \left(-2 \alpha_{0} \mathbb{H}\right)
$$

(b) Using (138), the covariance matrices are given by (119) to (121) with :

$$
Z_{\mathrm{m}}=\frac{1}{2 \sqrt{\alpha_{0} \mathrm{~T}_{1}}} \frac{\mathrm{U}\left(\frac{\mathrm{m}+1}{2}, \gamma\right)}{\mathrm{U}\left(\frac{\mathrm{m}-1}{2}, \gamma\right)} \quad ; \quad \dot{\mathrm{z}}_{\mathrm{m}}=\frac{1}{2 \alpha_{0}}
$$


The asymptotic behaviour (for $\mathrm{m} \rightarrow+\infty$ ) can be obtained for $\mathcal{Z}_{\mathrm{m}}$ in using (135)-(136):

$$
\mathrm{m} \rightarrow+\infty \quad, \quad Z_{\mathrm{m}} \sim \frac{1}{2 \sqrt{\alpha_{0} \mathrm{~T}_{1}}} \frac{1}{\sqrt{\mathrm{m}+2}} \exp \left(-\frac{1}{8} \sqrt{\frac{2 \alpha_{0}}{\mathrm{~m}}} \frac{\mathrm{T}_{0}}{\sqrt{\mathrm{T}_{1}}}\right)
$$

The characteristic function is given by (88), where the function $\Phi$ can be calculated by relations (103) to (105). Using (125) and (138), we get :

$$
\Phi\left(\mathrm{R}_{1}, \mathrm{R}_{2}\right)=\mathrm{e}^{-\frac{1}{4 \alpha_{0}} \mathrm{R}_{2}{ }^{2}} \sum_{\mathrm{k}=0}^{+\infty} \frac{\mathrm{A}_{\mathrm{k}}}{\mathrm{k} !}\left(-\frac{1}{4 \sqrt{\alpha_{0} \mathrm{~T}_{1}}} \mathrm{R}_{1}^{2}\right)^{\mathrm{k}}
$$

with :

$$
A_{k}=\frac{U\left(\frac{m-1}{2}+k, \gamma\right)}{U\left(\frac{m-1}{2}, \gamma\right)}
$$

Note that $A_{k}$ can be calculated by recurence on $k$.

(iv) Example 9 : Linear oscillator under parametric and external random excitations

Let us consider the equation (68). Functions $\Lambda$ and $\mathrm{H}_{0}$ are defined as in example 6 , and we have :

$$
\mu\left(r_{1}, r_{2}\right)=\left(g_{0}^{2}+\varepsilon_{m}^{2}\left(r_{1}^{2}+r_{2}^{2}\right)\right)^{-\gamma_{m}} \quad ; \quad \gamma_{m}=\frac{1}{2}+\frac{f_{0}}{\varepsilon_{m}^{2}}
$$

In the following we shall assume that the stationary response is a second order stochastic process. Therefore, the result of the example of the section 2.7 yields $m<\gamma_{\mathrm{m}}-1$.

Using the polar coordinates $r_{1}=r \cos \theta, r_{2}=r \sin \theta$, we can perform, with the help of (129) and (131), the calculation of the integral (123) which defines $X(p, q)$. We have :

$$
X(p, q)=\frac{1}{4}\left(\frac{g_{0}}{\varepsilon_{m}}\right)^{p+q+2} \frac{1}{g_{0}^{2 \gamma_{m}}} \frac{\Gamma\left(\frac{p+1}{2}\right) \Gamma\left(\frac{q+1}{2}\right) \Gamma\left(\gamma_{m}-\left(\frac{p+q+2}{2}\right)\right)}{\Gamma\left(\gamma_{m}\right)}
$$


(a) Using (143), the steady-state p.d.f (83) is written as :

$$
\rho_{\mathrm{Q}, \dot{\mathrm{Q}}}(\mathrm{q}, \dot{\mathrm{q}})=\sqrt{\operatorname{det}[\mathrm{MK}]}\left(\frac{\varepsilon_{\mathrm{m}}^{2}}{\pi \mathrm{g}_{0}^{2}}\right)^{\mathrm{m}} \frac{\Gamma\left(\gamma_{\mathrm{m}}\right)}{\Gamma\left(\gamma_{\mathrm{m}}-\mathrm{m}\right)}\left(1+2 \frac{\varepsilon_{\mathrm{m}}^{2}}{\mathrm{~g}_{0}^{2}} \mathbb{H}(\mathrm{q}, \dot{\mathrm{q}})\right)^{-\gamma_{\mathrm{m}}}
$$

with $\mathbb{H}$ given by (56), and where :

$$
\frac{\Gamma\left(\gamma_{m}\right)}{\Gamma\left(\gamma_{m}-m\right)}=\left(\gamma_{m}-1\right)\left(\gamma_{m}-2\right) \cdots \cdots \cdots\left(\gamma_{m}-m+1\right)\left(\gamma_{m}-m\right)
$$

(b) The covariance matrices are given by (119) to (121). Using $\Gamma(z+1)=z \Gamma(z)$ and relation (143), the calculation of relations (122) gives :

$$
Z_{m}=\dot{Z}_{m}=\frac{1}{2\left(\gamma_{m}-m-1\right)}\left(\frac{g_{0}}{\varepsilon_{m}}\right)^{2}
$$

\subsection{Conclusions}

This paper deals with the study of a large class of multi-dimensional Hamiltonian dissipative dynamical systems under parametric and external random excitations. We have obtained, for a gaussian white noise modelling of the random excitations, an exact steadystate probability density function for theses systems. When the Hamiltonian function of the conservative part has a radial form, one can explicitly calculate the constant of the normalization condition, the characteristic function and the covariance matrices, for any finite dimension of the system.

The examples given in the paper show clearly the effects of nonlinearities and random parametric excitations. On the other hand, the results which have been obtained show also how the normalization of this kind of stochastic dynamical systems, should be chosen for studying them in infinite dimensions. 


\section{References}

[1] H. RISKEN, 1989, The Fokker-Planck Equation. Second edition. Berlin : Springer-Verlag

[2] T. K. CAUGHEY, 1963, Journal of the Acoustical Society America, Vol 35, $\mathrm{N}^{\circ} 11$. Derivation and application of the Fokker-Planck Equation to discrete nonlinear dynamic systems to white random excitation.

[3] Y. K. LIN, 1967, Probabilistic theory of Structural dynamics. New-York : McGraw-Hill.

[4] T. T. SOONG, 1973, random differential equations in science and engineering. New-York : Academic Press.

[5] S. H CRANDALL and D. W. MARK, 1973, Random vibration in mechanical systems. New-York : Academic Press.

[6] P. KREE and C. SOIZE, 1986, Mathematics of random phenomena. Dordrecht, Holland : Reidel publishing company.

[7] T. K. CAUGHEY and F. MA, 1983, International Journal of Nonlinear Mechanics, Vol 17, $N^{\circ} 3,137-142$. The exact steady state solution of a class of nonlinear stochastic systems.

[8] T. K. CAUGHEY, 1986, Probabilistic engineering mechanics, Vol $1, \mathrm{~N}^{\circ} 1$. On the response of nonlinear oscillators to stochastic excitation.

[9] R. L. STRATONOVICH, 1963, Topics in the theory of random noise. New-York : Gordon and Breach.

[10] P. D. T. SPANOS, 1982, in Proceedings of the IUTAM Symposium on random vibrations and reliability. Frankfurt/Oder (GDR) (editor K. Henning). Berlin : Akademie-Verlag. Approximate analysis of random vibration through stochastic averaging.

[11] Y. K. LIN, 1986, Probabilisstic Engineering Mechanics, Vol 1, Nº1. Some observations of the stochastic averaging method.

[12] W. D. IWAN and P. D. T. SPANOS, 1978, American Society of Mechanical Engineers, Journal of Applied Mechanics, 45. Response envelope statistics for nonlinear oscillators with random excitation.

[13] J. B. ROBERTS, 1978, Journal of Sound and Vibration, 60, 177-185. The energy envelope of a randomly excited nonlinear oscillator.

[14] J. B. ROBERTS, 1981, Journal of Sound and Vibration, 74, 11-29. Transient response of nonlinear systems to random excitation. 
[15] J. B. ROBERTS, 1982, in Proceeding of the IUTAM Symposium on random vibrations and reliability, Frankfurt/Oder (GDR) (Editor K. Henning). Berlin : Akademie-Verlag. Energy methods for nonlinear systems with non-white excitation.

[16] J. B. ROBERTS, 1986, Probabilistic Engineering Mechanics, Vol 1, N $1,40-48$. Response of an oscillator with nonlinear damping and a softening spring to non-white random excitation.

[17] C. SOIZE, 1988, Probabilistic Engineering Mechanics, Vol 3, N²4, 196-206. Steadystate solution of Fokker-Plank equation in higher dimension.

[18] Y. YONG and Y. K. LIN, 1987, American Society of Mechanical Engineers, Journal of Applied Mechanics, Vol 54, 414-418. Exact Stationary-response solution for second order nonlinear systems under parametric and external white-noise excitations.

[19] T. K. CAUGHEY, 1971, Advances in applied mechanics, Vol 11, 209-253. Nonlinear theory of random vibrations.

[20] T. K. CAUGHEY and F. MA, 1982, American Society of Mechanical Engineers, Journal of Applied Mechanics, Vol 49, 622-632. The steady-state response of a class od dynamical system to stochastic excitation.

[21] T. K. CAUGHEY, 1963, Journal of the Acoustical Society America, Vol 35, 17061711. Equivalent linearization techniques.

[22] W. D. IWAN, 1973, International Journal of Nonlinear Mechanics, 5, 279-287.A generalizzation of the concept of equivalent linearization.

[23] P. D. T. SPANOS, 1981, Applied Mechanic Reviews, Vol 34, N 1 . Stochastic linearization in structural dynamics.

[24] Y. K. WEN, 1980, American Society of Mechanical Engineers, Journal of Applied Mechanics, Vol 47, 150-154. Equivalent linearization of hysteretic systems under random excitation.

[25] C. J. HARRIS, 1979, International Journal for Numerical Methods in Engineering, Vol 14, 37-50. Simulation of multivariate nonlinear stochastic system.

[26] M. SHINOZUKA, 1971, Journal of the Acoustical Society America, Vol 49, $\mathrm{N}^{\circ} 1$, 357-367. Simulation of multivariate and multidimensional random processes.

[27] M. SHINOZUKA and C. M. JAN, 1972, Journal of Sound and Vibration, 25, $111-$ 128. Digital simulation of random processes and its applications.

[28] F. POIRION and C. SOIZE, 1989, La Recherche Aérospatiale, 1, 41-61. Numerical simulation of homogeneous and inhomogeneous gaussian stochastic vector fields.

[29] R. L. STRATONOVICH, 1966, SIAM Journal of Control, Vol 4, N². A new representation for stochastic integrals. 
[30] N. IKEDA and S. WATANABE, 1981, Stochastic differential equations and diffusion processes. North Holland.

[31] A. FRIEDMAN, 1975, Stochastic differential equations and applications, Vol 1 and 2. New-York : Academic Press.

[32] K. ITO and H. P. Mc KEAN, 1965, Diffusion processes and their sample paths. Berlin : Springler-Verlag.

[33] H. P. Mc KEAN, 1969, Stochastic integrals. New-York : Academic Press.

[34] L. GUIKHMAN and A. V. SKOROKHOD, 1979, The Theory of stochastic processes. Berlin : Springler-Verlag.

[35] J. L. DOOB, 1967, Stochastic processes. New-York : John Wiley and Sons.

[36] R. Z. HASMINSKII, 1980, Stochastic stability of differential equations. Sijthoff and Noordhoff.

[37] I. S. GRASHTEYN and I. M. RYZHIK, 1965, Tables of Integrals, Series, and Products. New-York : Academic Press. 